\title{
Autonomous Processes in Assembly Systems
}

\author{
B. Scholz-Reiter (2), M. Freitag \\ Department of Planning and Control of Production Systems, \\ University of Bremen, Germany
}

\begin{abstract}
Today's assembly systems have to be flexible to adapt quickly to an increasing number and variety of products and changing demand volume. To manage these dynamics, flexible, reconfigurable, and autonomous assembly systems were proposed and partly realised in the last two decades. The flexibility and adaptability is realised by clustering the assembly system into subsystems and modules which get a certain degree of autonomy and control themselves in a decentralised way. This keynote paper will present the general principles of autonomy and the proposed concepts, methods and technologies to realise autonomous processes in assembly systems. Different approaches for design and autonomous operation of assembly will be explained and future trends towards fully autonomous components of an assembly system as well as autonomous parts and products will be discussed.
\end{abstract}

\section{Keywords:}

Assembly, Control, Autonomous process

\section{INTRODUCTION}

Due to increasing market dynamics, planning, optimisation, and control of assembly has become more challenging for manufacturing companies. Today, plans and schedules have to adapt quickly to a variety of products and changing market demands. But conventional structures and methods cannot handle changes, unpredictable events, and disturbances in a satisfactory manner.

To manage these dynamics inside and outside an assembly system, a number of novel concepts for both the physical system and the control system was proposed and partly realised in the last two decades. The most popular ones are Flexible Manufacturing Systems (see e.g. [48], [122], [123], Figure 1) and Reconfigurable Manufacturing Systems (see e.g. [53], [118], [84], [68]) on the hardware side and the Holonic Manufacturing System (see e.g. [105], [65], [91], [46], [11], [62], [63]) and the Biological Manufacturing System (see e.g. [97], [103], [102], [101], [100], [98], [104]) on the software side.

The recent concepts have a common characteristic: the assembly system - consisting of a network of assembly stations or cells, buffers, transport systems etc. - is clustered into subsystems and modules. These subsystems and modules get a certain degree of freedom to react on changes by themselves and adapt to new demands - they are more or less autonomous.

Autonomy in general means the independence of a system in making decisions by itself without external instructions and performing actions by itself without external forces. Approaches for (partly) autonomous systems are, e.g., autonomous production cells, automated guided vehicles, mobile autonomous robots, moving assembly stations, or dexterous robots with intelligent sensors.

These examples show that autonomy is not an absolute characteristic but relative to similar subsystems that act on the same hierarchical level of the entire system. That means the degree of autonomy of a subsystem is given (i) by the freedom of action that is given by the superior system level and (ii) by the ability of the subsystem to use this given freedom of action.

The benefit of introducing autonomous subsystems within an assembly system is reduced complexity of both the

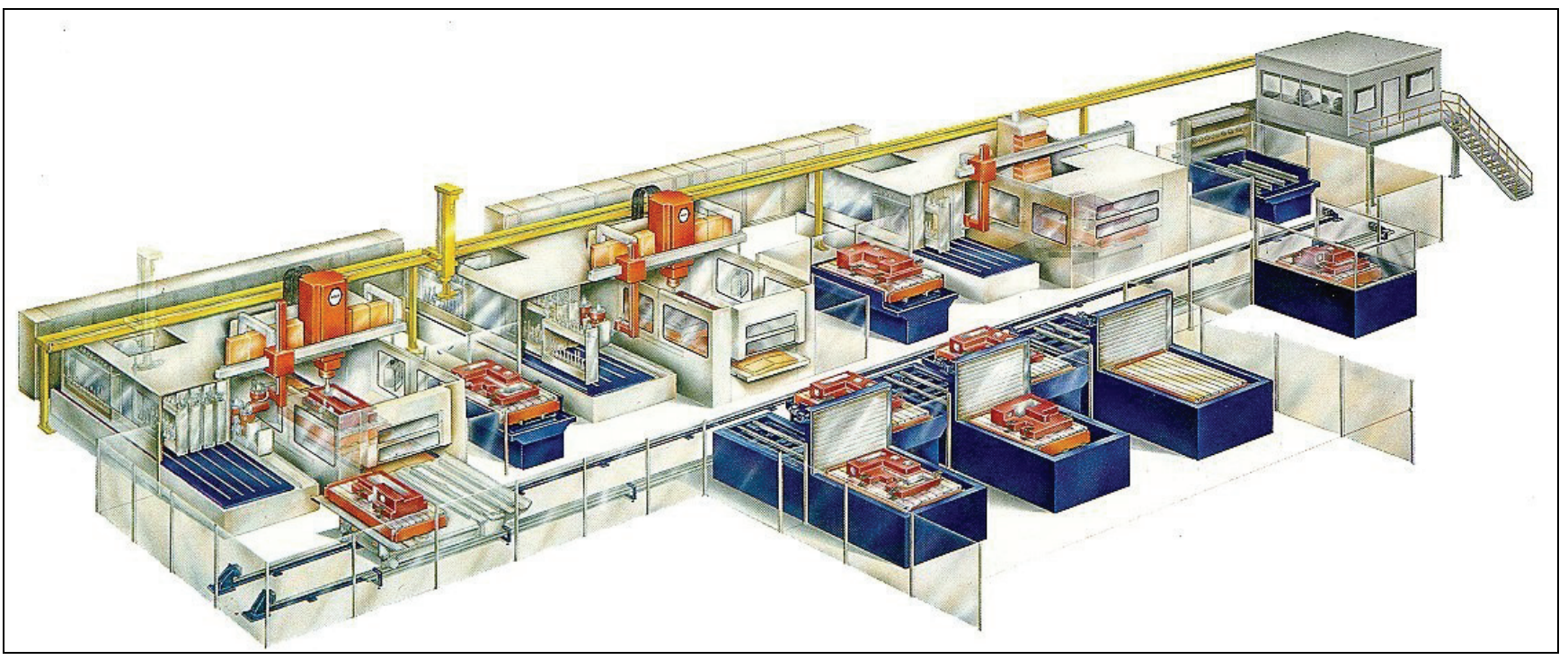

Figure 1: Flexible Manufacturing System [54]. 


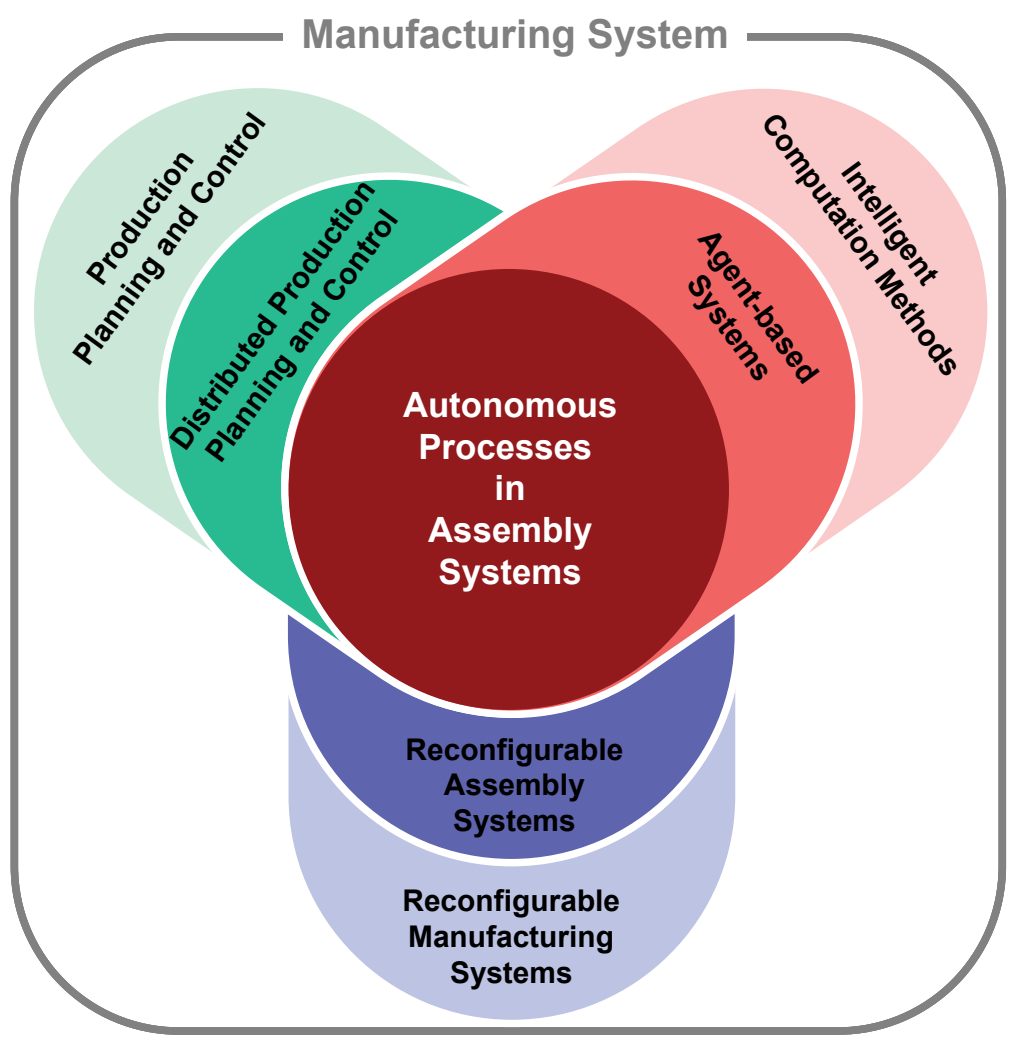

Figure 2: Focus of the keynote paper.

physical structure and the information system [10], [14], [117]. For the autonomous control of a subsystem, only local information is required. Due to the self- $x$ characteristics such as self-configurability, self-optimisation etc., autonomous subsystems are more flexible, adaptive, robust, and fault tolerant. They enable rapid response to customer needs [48]. These self-x characteristics will be reached by different methods from Artificial Intelligence and Artificial Life, e.g. multi-agent systems and swarm intelligence [69].

The application of autonomous subsystems is realised by recent information and communication technologies such as radio frequency identification (RFID), sensor technologies, wireless communication networks etc. These Ubiquitous Computing technologies enable a high flexibility and changeability of assembly systems to manage today's increasing requirements.

In parallel to the trend of enhanced automation using Ubiquitous Computing technologies and Artificial Intelligence methods, there is currently a shift back from automation towards more human involvement in planning and execution tasks [9]. Studies showed that the introduced automation is often not flexible enough to handle the dynamic demand of the market. The required flexibility and adaptability of the assembly system can only be achieved by manual assembly [9]. That means despite of the promising advantages of autonomous processes - we have to care for appropriate human participation during planning and execution of assembly. People are the most flexible resource of a company if a satisfying education and life-long learning is taken into account [9].

This keynote paper will give a survey of concepts with autonomous characteristics and will present the state of the art about autonomous processes in assembly systems. This topic is embedded into the following large research fields:

- Reconfigurable Manufacturing Systems inclusive assembly systems,

- Production Planning and Control inclusive distributed approaches,

- Intelligent computation methods inclusive multi-agent systems.

An overview on Reconfigurable Manufacturing Systems was given in the 1999 CIRP keynote paper by Koren et al. [53]. The general task of Production Planning and Control for assembly systems was presented in the 1990 CIRP keynote paper by Van Brussel [10]. Distributed approaches for Production Planning and Control were introduced by Duffie et al. [16], [17], [18], [19].

An overview on intelligent computation methods for manufacturing was given in the 1997 CIRP keynote paper by Teti et al. [94] and agent-based systems for manufacturing were presented in the 2006 CIRP keynote paper by Monostori et al. [69].

This keynote paper mainly focus on the intersection of these three research fields and thus deals with reconfigurable assembly systems and autonomous control concepts for assembly processes (Figure 2).

The keynote paper is organised as follows: After this introduction, section 2 gives an overview on principles of autonomy for both physical and control systems and introduces autonomous resources, products, and processes. Sections 3 to 6 are dedicated to the four levels of an assembly system and present the state of the art on the respective level (Figure 3 ).

Section 3 gives an overview on autonomous processes on system level which includes the design of autonomous assembly systems, scheduling and control of assembly orders and routing and transport of parts and subassemblies.

Section 4 deals with autonomous processes within both manual and automatic assembly cells. This also includes autonomy of workers and groups.

Section 5 presents research results on autonomous robots 
as well as autonomously controlled transport systems and section 6 gives an overview on autonomous devices such as part feeders and grippers.

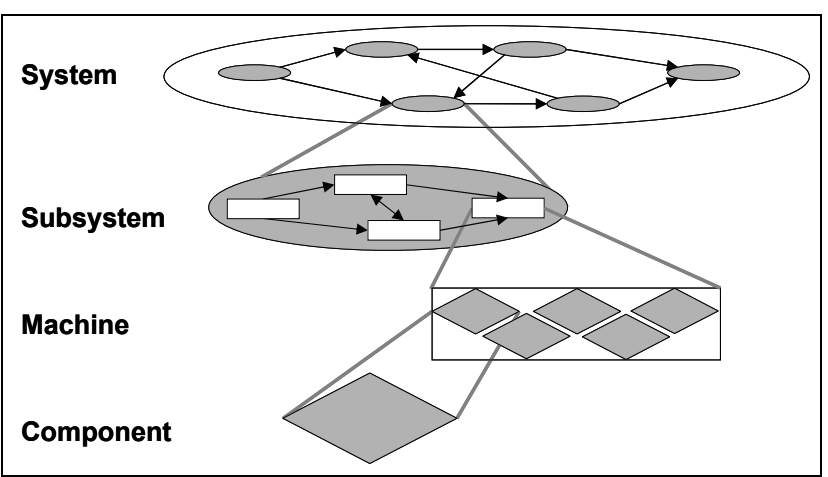

Figure 3: Levels of an assembly system.

Section 7 is dedicated to autonomous parts, subassemblies and products which are able to allocate resources by themselves and route autonomously through the assembly system using recent information and communication technologies.

Section 8 gives an outlook to future research in autonomous assembly and section 9 summarises the keynote paper.

\section{PRINCIPLES OF AUTONOMY}

Autonomy of a system implies two basic characteristics: First, independence from neighbour systems and from its environment, and second, the ability to control itself. The first characteristic can be reached by clustering an assembly shop into subsystems and modules with standardised interfaces. The second characteristic requires the decentralisation of the control system according to the granularity of the subsystems and modules.

\subsection{Physical Systems}

The need for clustering an assembly shop into subsystems and modules came up in the early 1990s when customised products and highly fluctuating demand could not be handled anymore by the former Flexible Manufacturing Systems (FMS), (see e.g. [48]). The quick changes in products, variants, and production volume required increased flexibility and adaptability of the assembly system [71], [48], [53], [86]. This led to Reconfigurable Manufacturing Systems (RMS), (see e.g. [53], [118], [84], [68]), which could be reconfigured regarding both capacity and functionality [48], [53]. The reconfigurability was realised by building autonomous assembly cells which were connected by flexible transport systems such as automated guided vehicles. An assembly system consisting of flexibly connected autonomous cells can be adapted quickly to changing production volume and product mix.

To increase flexibility and adaptability, the cells were built up of replaceable components and modules. The concept of "Plug \& Produce" helped to quickly introduce new or remove old units or devices in analogy to the "Plug \& Play" concept in the computer world [4]. "Plug \& Produce" is defined as the linking of system elements to ready-for-use production systems without manual configuration effort [27].

Furthermore, autonomous robots were developed which are able to recognise their environment by sensors, to coordinate their work with other robots and assembly equipment, and to adapt the assembly process if new products had to be assembled. Such degree of autonomy requires also sensor-equipped grippers and manipulators which are able to act like a human hand. The research on such dexterous hands and fingers is still in progress.

The remarks above show an improved granularity of autonomy [53]. To sum up, the following list shows examples for autonomous systems and resources respectively on the different system levels:

- System: e.g. shops as autonomous profit centres

- Subsystem: e.g. autonomous cells

- Machine: e.g. autonomous robots, AGV

- Component: e.g. dexterous grippers, artificial hands

These autonomous resources within an assembly system should be able to identify and locate themselves, to sense their environment, to communicate with other resources and with parts and subassemblies to be assembled or transported, and - last but not the least - to control themselves autonomously by using their integrated control system. These requirements are obvious for mobile autonomous robots and automated guided vehicles, but also needed for more conventional assembly equipment such as conveyors, stationary robots, part feeders etc. to realise autonomous assembly processes.

\subsection{Control Systems}

In the 1980s, the Flexible Manufacturing Systems (FMS) were controlled by a central control system. Within the concept of Computer Integrated Manufacturing (CIM), all product and production data were integrated into a central database to support the CAx und PPC systems with consistent information. Despite of extensive research in $\mathrm{CIM}$ and the obvious advantages of this concept, some researchers already recognised the drawbacks of central control in hierarchical structures. As an example, Duffie argued in his pioneering articles: "The complexity of such control systems grows rapidly with the size of the underlying manufacturing system. This complexity results in high costs for development, maintenance, operation and modification of the CIM control system. Alternatively, heterarchical control architectures lead to reduced complexity by localising information and control, to reduced software development costs by eliminating supervisory levels, higher maintainability and modifiability due to improved modularity and self-configurability, and improved reliability by taking a fault-tolerant approach rather than a fault-free approach." [16], [17], [18], [19]

With the upcoming need for Reconfigurable Manufacturing Systems and the clustering of the assembly shop into subsystems and modules in the early 1990s, decentralised control approaches and heterarchical architectures came to the fore. Furthermore, the implementation of intelligent control strategies became required in order to adapt the system [24]. The majority of researchers used agents and multi-agent systems either as design metaphor, as software technology or for simulation models [69]. This approach was boosted by the Intelligent Manufacturing System (IMS) programme and the Holonic Manufacturing System (HMS) concept developed within this programme (see e.g. [64], [105], [65], [91], [46], [11]). A HMS consists of distributed, autonomous, cooperative agents or holons. Three basic holons were defined: resource holons, product holons, and order holons [106] (Figure 4). The control architecture of an HMS lies between fully hierarchical and heterachical structures to compensate one of the major drawbacks of fully heterachical control structures: the lack of guaranteeing a certain global behaviour and performance. 


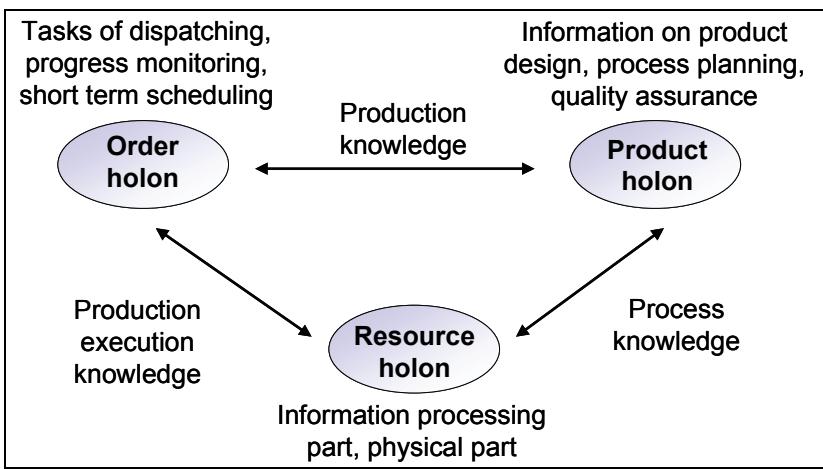

Figure 4: Reference architecture for Holonic Manufacturing Systems [69].

The multi-agent concepts used for decentralised assembly control include both powerful agents with planning and optimisation capabilities and simple agents with only a set of rules. The intelligent agents use planning and optimisation heuristics already known from central control systems such as genetic algorithms, neural networks, fuzzy logic etc. [94], [117]. The intelligence of a multi-agent system consisting of simple agents emerges on system level caused by local interactions of the single agents. This is realised by concepts from Artificial Life and Swarm Intelligence [94].

The flexibility of FMS is designed as a kind of corridor wherein the assembly system can be changed regarding product variants and production volume. This corridor is fixed and system changes beyond it require a laborious reconfiguration. An autonomous assembly system is designed as a dynamic system which moves along a trajectory given by the market demand. Prerequisite for such a dynamic adaptation of both assembly structures and processes is a real-time information feedback from the physical system. Such closed-loop control is traditionally used for mechanical and electrical systems on device and machine level. But due to the increasing market dynamics, the entire assembly system turns to a dynamic system which should be described by means of Dynamical Systems and Control Theory. These theories allow to model and analyse the dynamic behaviour of the assembly system and - in the context of autonomous assembly - the interactions between local autonomous decision-making and global emergence and self-organisation. Furthermore, Control Theory delivers methods and tools to design closed-loop controllers which replace the open-loop planning and control activities on system level [24].

Sensors are used to capture the current state of an assembly system and their autonomous resources and to feed these actual data back to the controllers. Sensor technology in assembly systems is usually used on component and machine level to realise, e.g., dexterous grippers and autonomous robots. In general, various types of sensors are used for different automated assembly operations [72]. Whereas existing sensors will be improved and new types of sensors will be developed, autonomous assembly additionally requires sensor integration, sensor fusion and artificial intelligence techniques such as artificial neural networks to process the sensor data. Furthermore, the integration of sensors within the control units of robots is required to replace human sensorial capabilities by machines [72].

Sensors on system level such as the traditional production data acquisition used for monitoring and control of assembly processes are outside the control loops of cells and machines [10]. An integration of system sensors into these inner control loops is required to turn the assembly system into an intelligent, flexible, adaptive, autonomous system, able to online assessing and curing process variations [10]. The more autonomous the assembly systems will be in the future, the more sensors are going to become indispensable [10].

\subsection{Convergence of Control and Physical Systems}

Most of the research work on distributed control considers a control system separated from the physical system to be controlled. Prerequisite for this approach is a virtual model of the physical world. Such a model requires a continuous feedback from the physical world to keep up-to-date. Otherwise, this model would represent a past system state and plans, schedules, and execution commands based on this model were already obsolete or even wrong when they were created.

A way to avoid such discrepancies between model und real world is to merge the control system and the physical system to be controlled (Figure 5). This would lead to fully autonomous systems and resources respectively where the benefit of modular and reconfigurable assembly systems and the advantages of decentralised control in heterarchical structures could be combined.

This approach is driven by two technological developments: Firstly, the trend to Ubiquitous Computing will lead to the so-called "Internet of things" where everyday objects get the properties of a computer in the internet: they can be identified and located and are able to communicate with other objects. Furthermore, they will get abilities to sense their environment, to process incoming data and to make decisions towards their intended use.

Secondly, the hypothesis recently emerged that intelligence requires a physical body. Research in the field of embedded agents concentrates on the realisation of artificial agents strongly coupled with the physical world and points out that physical instantiation and materials play an important role in intelligent behaviour. Applications for assembly are autonomous modular systems such as modular robots and self-assembling materials [69].

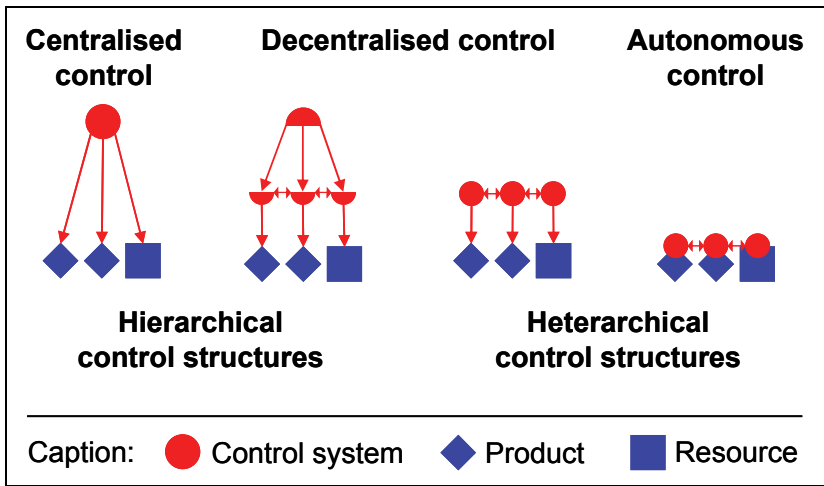

Figure 5: Convergence of control and physical systems.

\subsection{Autonomous Parts, Subassemblies, and Products}

Recent research projects investigate the introduction of autonomous parts and sub-assemblies which are able to allocate transport and assembly resources by themselves and - in doing so - route themselves through the assembly system. A first step towards autonomous parts and subassemblies is the tagging or embedding of identification devices. There are for example first prototypical integrations of RFID devices into die casting metal parts [12], [13]. Such identifiable parts can be connected with the ERP system to get product data, process plans and even data of customer orders. In a second step, some of these data can be directly kept on the part itself. For that, the 
simple RFID device has to be replaced by a chip with data storage, a processor, and a communication unit to exchange data between the part and the ERP system. The last step to a completely autonomous part is the integration of a software agent which is able to communicate with other parts and resources to coordinate all transport and assembly processes. The question whether the agent should be embedded into the physical part or could remain in a separate control system depends on the communication effort between different agents as well as the amount of data to be exchanged. A flexible solution is the use of mobile agents which are able to migrate from the control system to the physical object and vice versa. Consider the scheduling of assembly and the routing of the parts through the assembly shop: Due to the high communication and coordination effort between parts and resources, the mobile agents would migrate into the control system. If the final products leave the assembly system, the agents could migrate back to the physical objects to autonomously control the distribution process of the products.

Mobile agents are a specific form of mobile code and the software agents paradigm. They are active in that way they choose to migrate between computers at any time during their execution. This makes them a powerful tool for implementing autonomous parts and sub-assemblies in an assembly system. In general, a mobile agent is able to transport its state from one environment to another, with its data intact, and still being able to perform appropriately in the new environment. Mobile agents decide when and where to move next. A mobile agent accomplishes this move through data duplication. When a mobile agent decides to move, it saves its own state and transports this saved state to the next host and resume execution from the saved state.

To sum up, the enabling technologies to realise autonomous products are:

- Identification (e.g. RFID),

- Localisation (e.g. RFID reader, WiFi, GPS),

- Communication (e.g. WiFi, UMTS),

- Decentralised data processing (e.g. software agents),

- Sensor networks (e.g. visual sensors).

\subsection{Autonomous Processes}

The combination of autonomous resources on one hand and autonomous parts, subassemblies, and products on the other hand will lead to autonomous processes where parts and subassemblies allocate resources and coordinate their assembly by themselves (Figure 6).

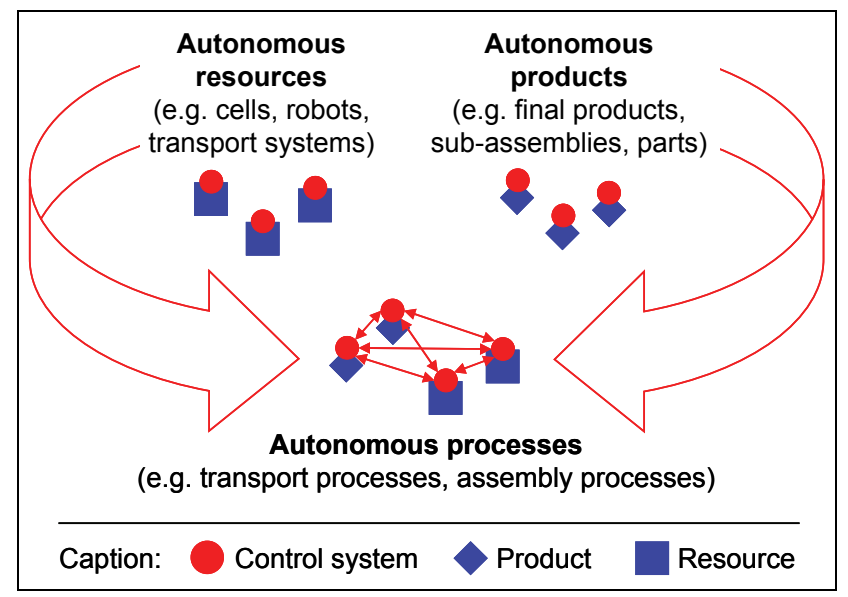

Figure 6: Autonomous processes.
Such autonomous processes would lead to highly flexible and self-adaptable assembly systems which could make a variety of customised products and deal with fluctuating demand with only little or even no human interventions [77].

\section{AUTONOMOUS PROCESSES ON SYSTEM LEVEL}

\subsection{Layout Design}

In general, four fundamental solutions in assembly design can be distinguished: (i) Manual assembly in small batch sizes at the one end and (iv) automated serial assembly at the other [24]. Between these extrema are two approaches for flexible assembly: (ii) a cell with a handling robot and (iii) a line with integrated NC machines [24]. The aim of designing autonomous assembly systems is to reach selfreconfigurability by both hardware and software. Static reconfigurability by hardware can be reached using building blocks or modules, modular machine tools etc. Dynamic reconfigurability by software requires modular, open-architecture control software [61]. Only the combination of reconfigurable hardware and software will lead to an autonomous assembly system. There are less design methodologies for such autonomous assembly systems that combine the physical system and the control system. Koren et al. pointed out the following design tasks [53]: definition of the system-level configuration task; splitting a machine into a set of autonomous functional units; standardised interfaces for mechanics, power, and information; design of open control architectures [53].

To evaluate a chosen shop layout, model-based simulation is a powerful tool to test the performance of the designed system [115]. In addition to this traditional simulation task, autonomous assembly systems require an analysis of their dynamic behaviour due to the complex interactions between autonomous entities on different system levels. This can be done for a specific assembly system by discrete-event simulation [117]. But such simulation results do not provide general statements about stability and robustness of the system. Therefore, research is needed into a mathematical description of the possibly complex behaviour of autonomous assembly systems [10]. Mathematical closed-form solutions such as controltheoretic models [23], general flow models [6], [78], Markov chain models and queuing models are good candidates [10], [115].

One of the first approaches for dynamic reconfiguration of manufacturing systems is the Biological Manufacturing System (BMS) concept (Figure 7).

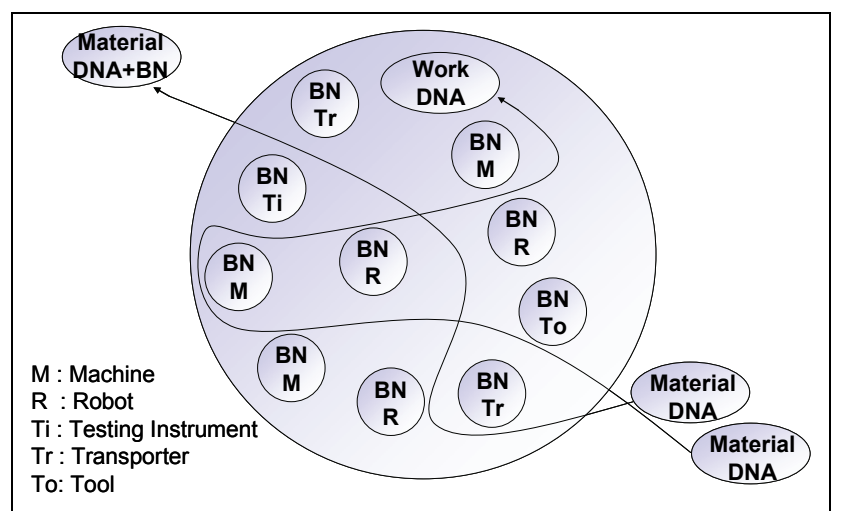

Figure 7: Biological Manufacturing System concept [97]

Ueda at al. introduced this concept to deal with dynamic changes in external and internal environments using biologically inspired ideas such as self-growth, self- 
organisation, adaptation, and evolution. They modelled and simulated a BMS at floor level focussing on system configuration. Their simulation results showed adaptive behaviour to changes in product demands and malfunctions of manufacturing cells. The BMS concept provided the possibility of dynamic reconfiguration of the manufacturing system [97], [98].

This approach has been continued towards an autonomous layout reconfiguration using potential fields around the production elements (Figure 8 ). In this system, all production elements can move freely on the production floor using self-organization in order to adapt to fluctuations such as the diversity of product demands and the malfunction of machines. The effectiveness and feasibility of this system is demonstrated by computer simulations and by a prototypical mini-factory consisting of small autonomous robots [100], [101], [102].

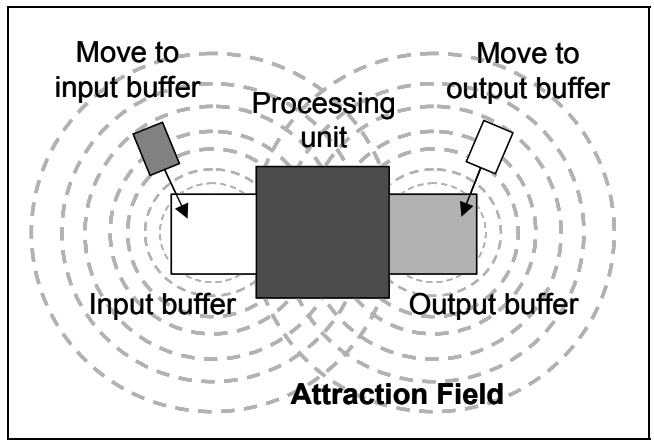

Figure 8: Autonomous layout reconfiguration using potential fields [101].

Ueda et al. enhanced the BMS concept to reinforcement learning approaches including classifier systems and stochastic learning automata. Simulation results demonstrated that the proposed model can achieve global objectives such as "maximise the throughput" and "minimise the due date deviation". Ueda et al. argued that real-time scheduling can be practically realised by augmenting the BMS with learning functions [98]. The BMS concept was also used for planning and control of make-toorder production to evaluate and control the range of time and cost constraints that the system is able to complete [102].

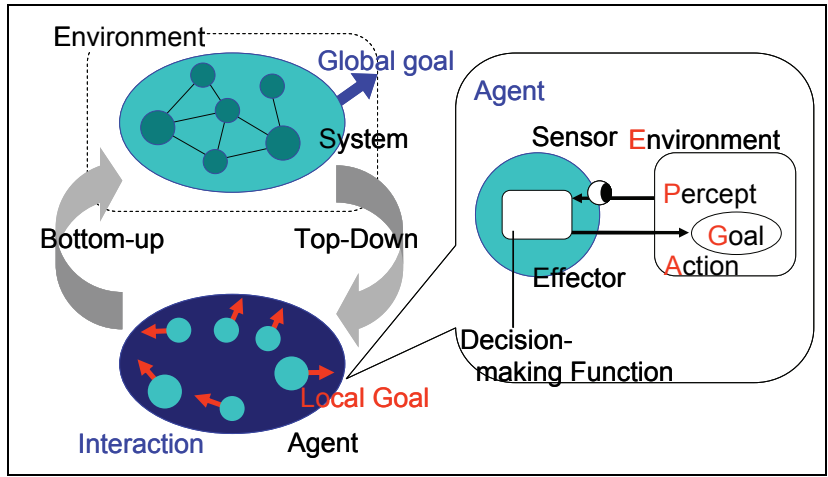

Figure 9: Biological Manufacturing System concept with bounded rational agents [103].

Latest work based on the BMS concept introduced bounded rational agents to improve the system performance (Figure 9). The effectiveness of the proposed idea was examined using an ant system simulation and a self-organization-based BMS simulation. The behaviour of bounded-rational agents resulted in an altruistic emergence of role sharing among rational and boundedrational agents avoiding local conflicts and competition [103].

Kondoh et al. proposed a cellular manufacturing system as a rapid prototyping and decision-making tool for configuring production facilities and product task assignment. At the conceptual design stage of the cellular manufacturing system, there is no decision about facility configuration and product or machining task assignment. This will be determined by self-organisation at the operation stage. The cellular manufacturing system is able to adapt the facilities configuration to changing manufacturing requirements [49], [50], [51], [52].

Feldmann et al. developed a theoretical model for designing "Plug \& Produce"-able modular production systems. Such modular systems are built-up of components which are highly modularized in a mechanical, electrical, and informational way. But most works on modular production systems focus on the physical system plus material flows and neglect the control system and information flows. Feldmann et al. proposed their holistic model that covers the physical structure, processes and energy supply as well as control units for processes, flows and logistics [29]. They enhanced their model towards a specification of an agent platform that coordinates the modules and supports the adaptability of the production systems [30].

An approach to assess the flexibility of manufacturing systems based on Discounted Cash Flow estimates for a number of market scenarios over a time horizon is presented and applied in a case study from an assembly plant of the automotive industry. Additionally, an algorithm for planning the changes of production system with the objective of minimizing system's lifecycle cost is presented in [1].

\subsection{Scheduling and Control}

Scheduling of assembly systems is characterised by high complexity (number of orders, variety of products, variety of resources) [10]. The general task of assembly scheduling is the assignment of operations to workstations, allocation of resources, and building a schedule [10]. The assembly scheduling problem is similar to the known job shop scheduling. But the assembly scheduling is even more complicated due to the fact that in an assembly sequence are often many candidate operations which can be performed next [10]. In autonomous assembly systems, the schedule must be reactive to deal with uncertainty and disruptions. Disruptions should be treated at the system level where they appear [10]. In general, the assembly scheduling problem is NP-complete and requires heuristic approaches to get feasible solutions in adequate time [10].

In an assembly control system with reactive scheduling capabilities, the different components cannot be independently programmed since an assembly system is a distributed system and the different workstation programmes will run in parallel, exchanging information for synchronisation and coordination purposes [10]. One approach is a completely heterarchical control system where intelligent products and parts drive their own production in cooperation with intelligent manufacturing resources [106]. By locating decision-making where information originates, global information is claimed to be reduced to a minimum, scheduling becomes dynamic, machines and parts become intelligent entities that cooperatively interact, and the overall system is decomposed into functionally simplified, modular parts [19]. The key advantage of heterarchical manufacturing control is the much-reduced exposure of the software components in the system [106]. 
Duffie et al. developed a heterarchical control system for an experimental production system consisting of a machining cell and an assembly cell connected by a pallet transportation system consisting of two robots and a highspeed vehicle for moving pallets between cells [18]. Global information is reduced to a minimum in the system. Parts to be manufactured are programmed as intelligent entities that cooperatively interact with intelligent robots and processing machines. Human entities have also been included that cooperate as colleagues of the other entities in the system. This system design resulted in reduced complexity, higher fault tolerance, shorter development times and lower development costs [18]. Based on this and further preliminary work, Duffie et al. developed and enhanced distributed scheduling heuristics and analysed their performances using both simulation models and different experimental manufacturing systems [19], [20].

The already mentioned Holonic Manufacturing paradigm mostly focuses on the control level and, more specifically, on the concept of autonomous cooperating agents (holons) operating in the shop floor (Figure 4). The design, the implementation, the use and the reconfiguration of the control are involved in the paradigm [48]. A comprehensive survey of the different Holonic Manufacturing Systems activities is beyond the scope of this keynote paper. For an introduction of the concept see, e.g., [105], [65], [91], [46], [11], recent work is contained in [62], [63].

Markus et al. introduced a market mechanism for coordinating the activities of intelligent agents that pursue their own interest by operating under bounded rationality in a changing, hardly predictable environment. The market model is used for solving dynamic order processing and scheduling problems: conflicts between local scheduling agents are resolved by negotiating and bargaining on simple common terms of tasks, due dates and prices. [64]

A multi-agent software system was developed in the context of the ESPRIT IV Project called RIDER (Real-Time Decision Making in Manufacturing) [70]. Upon the occurrence of an event (e.g. machine breakdown, new orders, etc.), autonomous agents use a mechanism to generate local alternatives and follow a message exchange procedure to build decision trees, which are traversed and evaluated via user defined cost-based objective functions. Each agent is programmed to perform a specific set of complex actions: as an example, the agent supervising the weaving department of the cable manufacturer [15] may address both nesting and scheduling optimization problems in the weaving process and then inform the upstream agents about the alternative nesting schedules it has generated.

Seliger et al. considered the assembly as the downstream end of the supply chain [83]. They proposed an agentbased approach to integrate suppliers and forwarders into assembly control to smooth fluctuations and to shorten delays of deliveries. Seliger et al. used control loops to (i) adjust transport capacity to the current demand in assembly and (ii) to deal with changes and uncertainties in suppliers' behaviour. They designed a hierarchy of different agents, defined conversation guidelines and simulated both the transport and assembly processes and the agent-based control logic. The simulation results showed lower inventory by dynamic adjusting of the required transport capacity [83].

A comprehensive survey of the different agent-based control systems for manufacturing is beyond the scope of this keynote paper. For an introduction and a literature review see the 2006 CIRP keynote paper by Monostori [69].

Despite of the mentioned advantages of distributed control in heterarchical structures, there is only little work in analytical descriptions of the global system behaviour that emerges from the local interactions of the high number of autonomous entities. Duffie et al. used continuous control laws instead of heuristics and modelled a distributed manufacturing system by nonlinear, discontinuous differential equations. They analysed the dynamics of the system and found that the system behaviour is seemingly chaotic but favourable and converges to decisions in realtime with known performance [23]

Armbruster et al. developed a mathematical description of an autonomously controlled production network. A fluid model with limited service rates in a general network topology was derived and compared to a discrete-event simulation model. Whereas the discrete-event simulation of production networks is straightforward, the formulation of the addressed scenario in terms of a fluid model is challenging. Here it is shown, how several problems in a fluid model formulation (e.g. discontinuities) can be handled mathematically. Finally, some simulation results for the pheromone-based control with both the discreteevent simulation model and the fluid model are presented for a time-dependent influx [6].

\subsection{Routing and Transport}

The material flow through an assembly system can be classified into the transport of (partly assembled) products from station to station or from cell to cell and the transport of parts and tools to the stations or cells [61]. Material flows in assembly systems also include the internal transport within cells and the part feeding. These transport processes will be considered in sections 4-6 according to the structure of this keynote paper

Duffie et al. developed a fully-distributed system-level control architecture for dispatching, routing, and collision avoidance of multiple vehicles moving in a guideway network formed by a multitude of propulsion units [21], [22]. The moving vehicles are completely passive and are controlled by the cooperating propulsion units. The applied routing algorithm does not require a global map of the transportation network. The guideway network and the communication network are unified to combine systemlevel and vehicle control to realise on one hand high vehicle speeds and short response times and on the other hand a self-configuring, extensible, fully distributed control. This system architecture was used for material transfer within an experimental manufacturing system to deliver tools to and from machines.

Feldmann et al. developed a system of automated guided vehicles (AGV) with distributed, decentralised control [26] (Figure 10). The AGVs transport parts and subassemblies between assembly stations and cells whereby they autonomously decide about their particular routes. The AGVs have laser scanners to determine their position on the shop floor and infrared sensors to recognise obstacles. Each AGV has a control system by its own which realises not only the routing and control of the AGV but also all decision-making and coordination tasks for the processing of transport orders and collision avoidance. Agents are used to schedule transport orders in that way that all AGVs are evenly utilised. For this, agents negotiate between AGVs and stations in real time. The algorithms for decision-making are kept in agents that accompany the parts and subassemblies by migrating from one station to another. This system of autonomous AGVs with agentbased, distributed control achieves a high and constant utilisation of the AGVs even in a highly dynamic environment and can autonomously compensate breakdowns of single AGVs [26].

Feldmann et al. developed a decentralised, self-organising and "Plug \& Produce"-able material flow system which is based on autonomous modules [27], [28] (Figure 11). Each 
module automatically possesses knowledge of all other modules in the system and the way they are coupled. Modules, which will be added or removed, can be recognized automatically. In addition to this structure recognition, products' working plans and stations' process lists are made available to each junction of the material flow system. Using this information, the junctions are able to determine the next processing step of an incoming part and look for an appropriate assembly station. To identify a part uniquely, active or passive devices can be applied. Active identification devices can be used to keep product and process data directly on the part. In contrast, passive devices only provide an identification number and thus need connection to a database to get the required information [28].

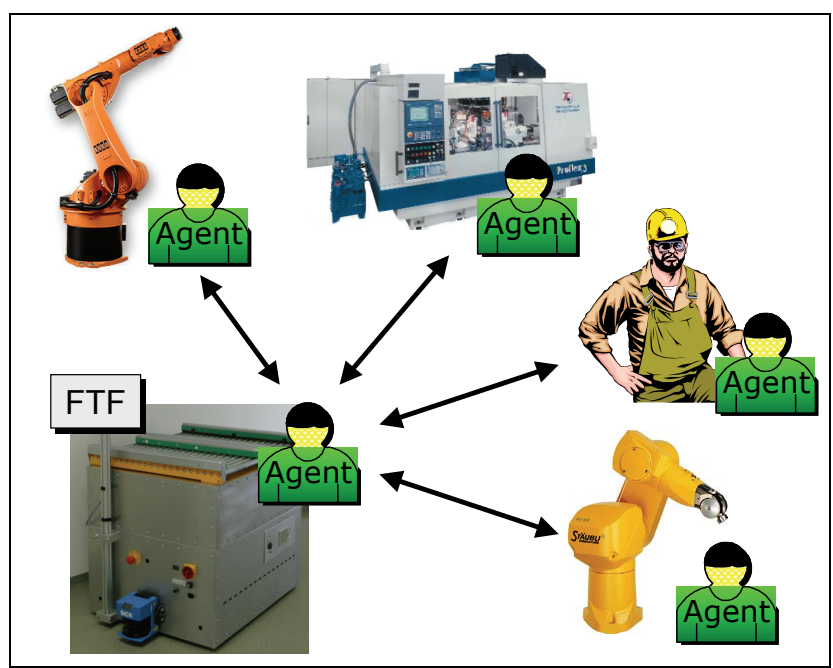

Figure 10: Automated guided vehicle system with distributed, agent-based control [26].

The junctions of the material flow system actively guide the moving parts. They contain of entrance and exit units and a router unit to guide a part from its entrance gate to the autonomously chosen exit gate. Therefore, the router identifies the part and reads the required data to determine the destination station. Feldmann et al. applied two decentralised routing strategies: a process-oriented and an agent-based strategy. Both routing strategies are able to deal with plan changes and to compensate disturbances by finding alternative processes and assembly stations. In doing so, the assembly system achieves autonomously a very high throughput performance [28].

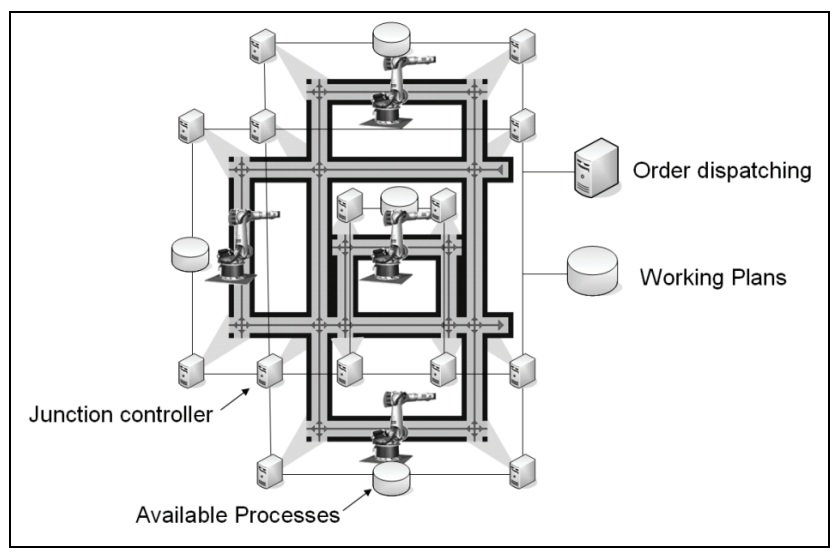

Figure 11: Decentralised, self-organising and "Plug \& Produce"-able material flow system [27], [28].

\section{AUTONOMOUS PROCESSES IN SUBSYSTEMS}

In general, assembly cells can be classified into manual, automatic, and hybrid cells. The highest flexibility and adaptability of an assembly system can be realised by manual assembly stations. Manual assembly is still dominant in various fields. Final assembly of automobiles is a typical example [61]. The efficiency of manual assembly can be increased by decentralised team or group structures. This means the turning away from hierarchical structures and the introduction of self-organisation and self-optimisation within the group [24].

The combination of automated and manual work cycles leads to so-called hybrid assembly systems. The employee undertakes complicated assembly tasks self-dependently while the flow of materials and quality relevant or nonergonomic tasks are carried out automatically at separate cells [24]. Hybrid or cooperative cells combine the accuracy and speed of robots with the flexibility and reliability of human workers. This combination is especially useful for complex assembly and handling tasks [55].
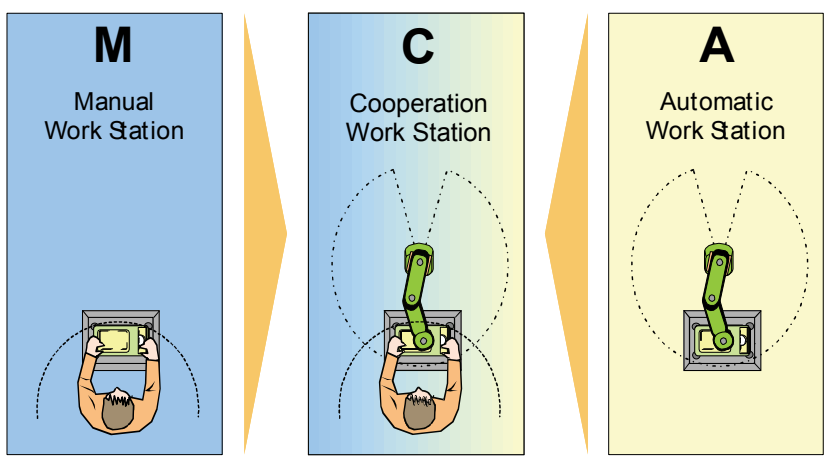

Figure 12: Combination of a manual and an automatic work station [55].

\subsection{Manual assembly cells}

Schuh et al. developed a concept for logistics control in manual assembly called Adaptive Logistics. It strengthens the involvement of operative workers in decision-making processes. The required information is presented via mobile assistance systems. Additionally, multi-agent systems allow for a detailed capacity planning and yield a complementary submission of recommendations. Thus operative workers take the role as the central decisionmaking agent [81], [82].

Spath et al. developed a new organizational approach for manufacturing companies called adaptive business labour organization. This approach is characterized by flexibility for adjustment and adaptation to a rapidly changing surrounding. The organization is based on process cells, which are able to network flexibly according to market requirements. It forms a framework for the responsible integration of operative employees in continuous planning processes. Team-oriented Information Systems and Visual Management make targets transparent and show up-todate status of key indicators. These indicators expand into flexible working times and dynamic compensation models [87].

\subsection{Hybrid assembly cells}

Krüger at al. proposed a hybrid assembly cell to overcome the separation of man and robot and to combine the accuracy and speed of robots with the flexibility and reliability of human workers. They developed a system based on digital 3D image analysis which supervises the common working area of robot and man [55] (Figure 13). 


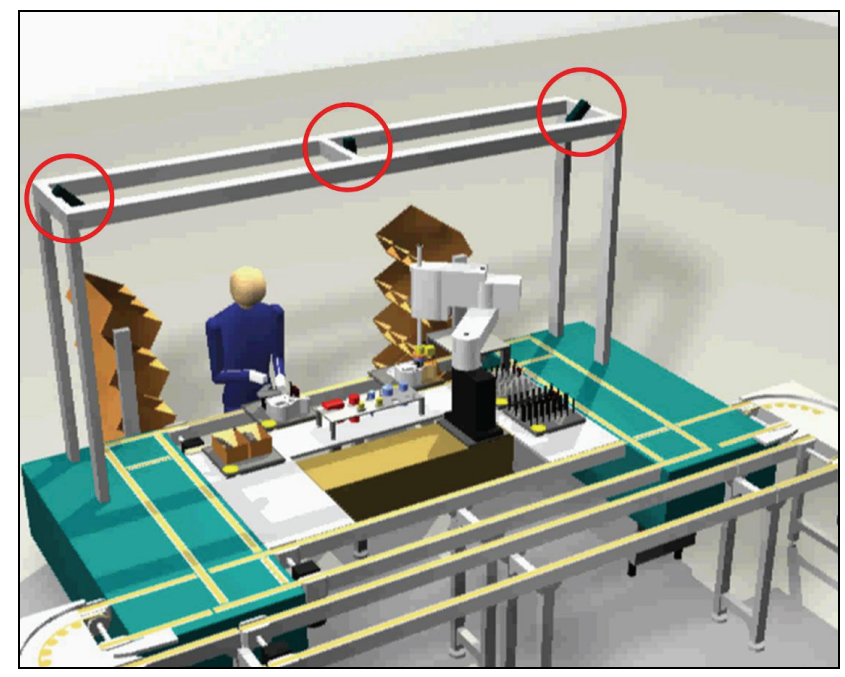

Figure 13: Cooperative work place with location of the surveillance cameras [55].

Krüger at al. continued their work and presented the novel collaborative robot system "Cobot" capable of sharing the workspace with the human co-worker and collaborating with him through direct physical contact. The idea is to combine human flexibility, intelligence and skills with the advantages of sophisticated technical systems. Intelligent assist systems (IAS) represent a novel class of assembly systems capable of working with human operators in two modes: workplace sharing and time sharing [56] (Figure 14).

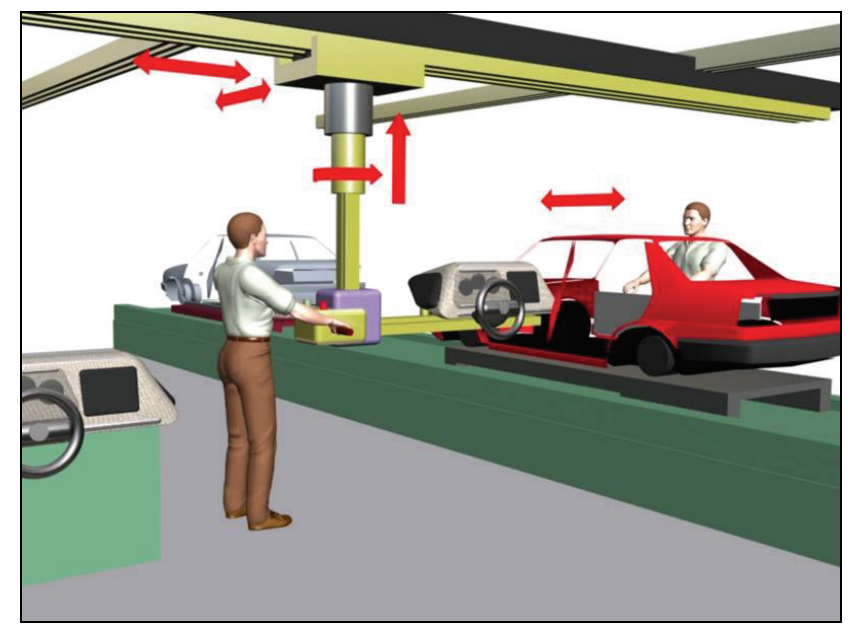

Figure 14: Conceptual "Cobot" construction for flexible automotive assembly [56].

\subsection{Automatic assembly cells}

Duffie et al. compared hierarchical and heterarchical control strategies for flexible manufacturing cells [17]. They introduced a dynamic part-oriented scheduling where the scheduling decisions were shifted from the production preplanning to the cell control system. Furthermore, they changed from the traditional machine-oriented control philosophy to a part-oriented control. Part-oriented scheduling infers that the parts make requests for machines. They implemented this scheduling algorithm in both a hierarchical and a heterarchical control system and compared the performances. The heterarchical system outperformed the hierarchical one in the areas of modifiability, fault tolerance, cost, complexity and memory requirements [17].
Automated guided vehicles and mobile robots can be used as moving assembly stations [61]. By this way, dynamically configurable systems have become available. Schippner et al. developed the Mobile Autonomous Robot Twente (MART) [73], [61]. The concept of the Mobile Autonomous Robot Twente consists of a vehicle-based 4 degrees of freedom assembly robot, a part supply station, and a navigation system. The mobile robot carries the assembly manipulator and a number of product carriers. Assembly is performed on board. The manipulator is controlled by distributed software that can be downloaded via radio link [61]. Hirabayashi proposed a system of travelling assembly robots where three sets of robots are moving around on a rail track [41], [61]. Hitachi realised an assembly system using AGVs which work as part feeders, assembly tools, universal robots etc. This system can change its configuration using a precision autonomous robot system that does not require a teaching process [93].

Arai et al. propose a Holonic Assembly System with "Plug \& Produce" capabilities. This is a methodology to introduce a new unit or device into an assembly cell easily and quickly. It is designed by analogy of the "Plug \& Play" concept in the computer world. Arai et al. verify their concept by experiments with robots and a belt conveyor. Here, a robot will be installed to an existing cell in a short time [4]. When a new device, e.g. a robot is installed into the assembly cell, calibration should be made. Arai et al. propose an automated calibration system of relative position/orientation based on the Direct Linear Transformation method using two CCD cameras. The cameras are freely positioned, and then a set of motions is commanded to each manipulator. By detecting the motion with the cameras, the relative position of the two robots is obtained [5] (Figure 15).

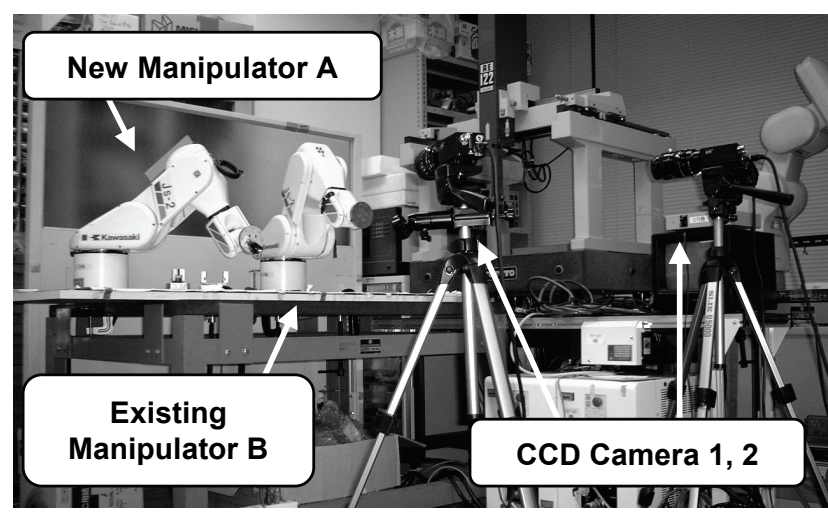

Figure 15: Automated calibration system for a "Plug \& Produce" assembly cell [5].

Scholz-Reiter et al. proposed a methodology to reactively generate process plans for flexible disassembly of obsolete appliances [75]. They classified the disassembly process to determine necessary disassembly information. A special database and information retrieval method has been developed to keep and process this structured disassembly information. Because of the existing uncertainties during disassembly processes, the process plans have to be flexibly adapted to the current state of the appliance to be disassembled. Scholz-Reiter et al. proposed the generation of high level and low level process plans based on previously generated product models and assumptions about possible uncertainties. During the high level process planning, all possible and feasible disassembly sequences are generated and represented by means of Disassembly Petri Nets. The low level process planner translates the macro modules of the Disassembly Petri Net into micro modules of the 
disassembly operations programme to implement the process plan into the robot controller. In addition, the tasks of low level planning are scheduling, defining parallelism among disassembly operations and collision avoidance [75].

Scholz-Reiter et al. applied their reactive process planning method to a flexible robot-based disassembly cell for obsolete TV sets and monitors [74]. The cell consists of a disassembly robot, a handling robot, an intelligent vision system and the software for flexible online planning and control of the disassembly process. Considering, for example, the separation of the back cover from a monitor, the vision system has to recognise the position and the type of screws to be taken out. The type of screws defines the tool and the position of screws defines the movement of the tool. This information is used for the online process planning of the disassembly process. The disassembly robot picks the right tool, moves to the positions of the screws and takes them out. After unscrewing, a special suction device sucks the screws and moves them to a repository. Then, the handling robot grips the back cover, detaches it and moves it to a repository too. This procedure requires product information about the monitor. This information is kept in a Bayesian Network that represents a kind of expert system. If there is not sufficient information to disassemble the monitor by screw drivers, there is a second option to remove the screws by a special core breaking tool. The decision about the procedure to be chosen and the generation of the appropriate process plan and the corresponding robot programme will be done online as reaction of the type and the state of the monitor to be disassembled [74].

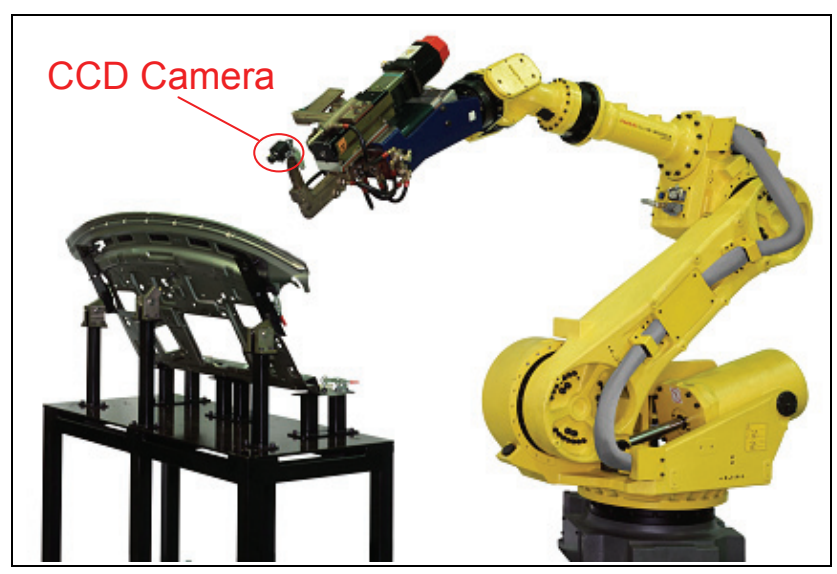

Figure 16: Experimental robot system with CCD camera [110].

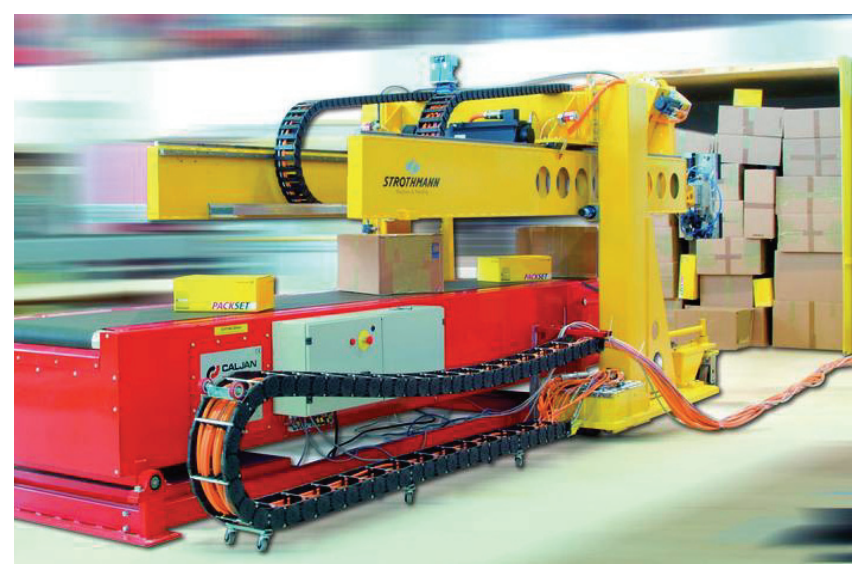

Watanabe et al. introduced a new method of adapting the virtual world of an offline programming model to an actual robotic cell by attaching a CCD camera to the robot. This method requires no specific camera attachment location or optical camera calibration. Furthermore, there is no operational requirement for setting robotic camera location. Robot motion is autonomously generated to identify the camera view line. The view line is adjusted to pass through the designated target point, utilizing visual feedback motion control. This method calibrates reference points between the virtual world of an offline model to an actual robotic cell [110] (Figure 16).

\section{AUTONOMOUS MACHINES}

Autonomous machines in assembly are mainly autonomous robots for handling and assembly but also autonomously controlled transport systems.

Papakostas et al. described the state of the art as follows [71]: "The automation of assembly tasks requires that some of the sensory "intelligence" of the human being is incorporated into the next generation of industrial robots. One challenge of research in robotics is to automate the process of multi-sensor supported assembly by gradually enabling the robot and sensor system to carry out the individual steps in a more and more autonomous fashion. The typical hierarchical robot control system architecture for realizing such systems was explained in details in [34]. However, a fully automatic assembly under diverse uncertain conditions can rarely be realized without any failure. Several projects on communicative agents realized with real robots have been reported, e.g. [42]. In the projects described in [43] and [7], natural language interfaces were used as the "front-end" of an autonomous robot. If constrained natural language is used to realise a limited number of robot operations, special steps can be taken, e.g. by only recognizing nouns in an instruction and listing the possible actions based on a pre-defined knowledge database [120]. In the SAIL project [7], levelbased AA-learning combined with attention-selection and reinforcement signals was introduced to let a mobile robot learn to navigate and to recognize human faces and simple speech inputs. In [8], the main system architectures were compared, and an object-based approach was proposed to help manage the complexity of intelligent machine development. In the Cog project [88], the sensory and motor systems of a humanoid robot and the implemented active sensing and social behaviours were studied. To overcome the limitations of this approach, the concept of the "Artificial Communicator" was developed."

Fujita presented a human-like assembly robot which autonomously interprets an assembly job by simply observing a sample object and thereby generates a task

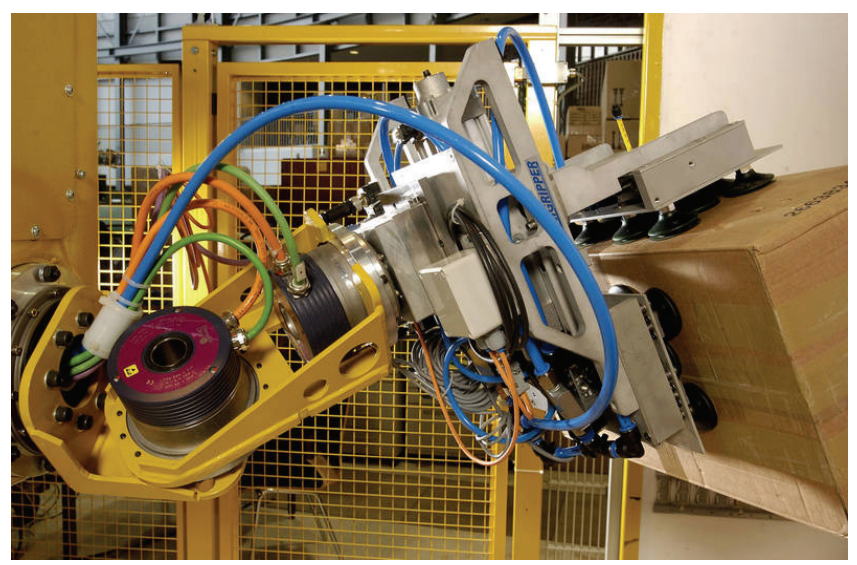

Figure 17: Robotic system for unloading swap bodies. 
sequence and action procedure. By following this action procedure, the robot can then assemble a replica of the sample. With the aid of sensors and detailed knowledge of executable tasks, the robot is able to grasp a targeted object which is not precisely placed and securely attach it to a subassembly at the desired position [39].

Scholz-Reiter et al. developed a robotic system to handle incoming vendor parts and subassemblies packet in cases and delivered in a swap body [79]. A laser scanner scans the container interior to recognise positions and orientations of the cases. The robot controller uses this information to choose a case to grip first and move the gripper to this item. The robot removes the case from the swap body and puts it on a conveyor belt for further transport into the assembly system (Figure 17).

Watanabe et al. proposed a new kinematic calibration method to automatically improve absolute positioning accuracy of robots [111]. Key points of the method include autonomous measurement and the automatic generation of measuring poses. A new visual feedback motion control method of the robot is proposed to achieve accurate measurement (Figure 18). Watanabe et al. proposed an algorithm to improve the condition of measuring poses automatically. The effectiveness of the proposed methods and algorithm was investigated through experiments with actual robots [111].

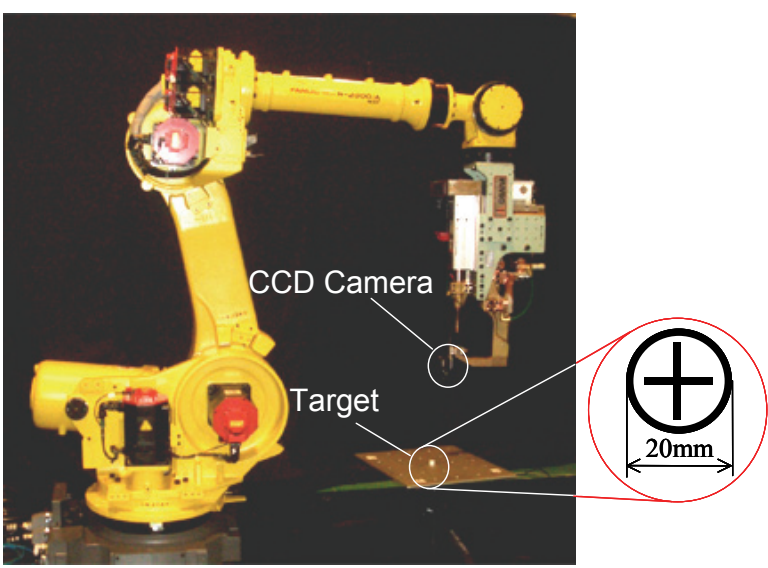

Figure 18: Kinematic calibration method positioning accuracy of robots [111].

Duffie proposed an approach to the design of distributed machinery control systems [16]. He specified the system requirements, partitioned the system into autonomous processes, allocated these processes to different processors, and chose a communication network for the interaction of the processes and processors. $\mathrm{He}$ exemplarily applied his design approach to a material handling system where successive rollers must be driven at the same or different speeds with the capability to index one with respect to another [16]

\section{AUTONOMOUS DEVICES}

An ideal assembly system should satisfy the three specifications: productivity, flexibility, and dexterity [61]. Whereas productivity and flexibility are guaranteed on system and subsystem level, dexterity has to be realised on device level. This includes all kinds of manipulators such as part feeders [61] and grippers [113]. The aim is the design of intelligent and autonomous devices, consisting of mechanically components, sensors, actuators and microcontrollers [25].

Arai et al. propose an autonomous control of non-grasping manipulators. They consider the release of a part from the manipulator to transport the part to a desired position and orientation as precisely as possible. Arai et al. control the motion and the destination of this part using visual feedback. Cameras measure the initial velocity and the final position of the part and feed this information back to the manipulator controller. The controller uses the data to adapt the manipulator's release motion. After several trials the robot can manipulate the part to the desired position with certain accuracy. [3]

Fleischer et al. introduced autonomous principles into micro assembly. They proposed modular micro assembly plants with flexible handling technique. The application of intelligent and autonomous assembly devices and the use of universal micro grippers with automatic changing systems are the basis for an efficient and economic micro assembly [32].

Feldmann et al. described two intelligent devices for an autonomous adaptation on different parts or subassemblies to be handled [25]. Firstly, they developed a flexible three-finger gripper with tactile sensors at the finger tips and an integrated vision system to recognise the working area and the work piece and to supervise the assembly procedure. This is done by an integrated camera and an embedded microcontroller mounted directly onto the gripper. The gripper knows the complete assembly task and is therefore completely independent of any central and external control (Figure 19). Secondly, Feldmann et al. developed a system for flexible feeding of varying parts. They used pressure sensitive sensor foils to identify the type and position of parts to feed. Both devices provide high flexibility and significant decreases of setup times [25].

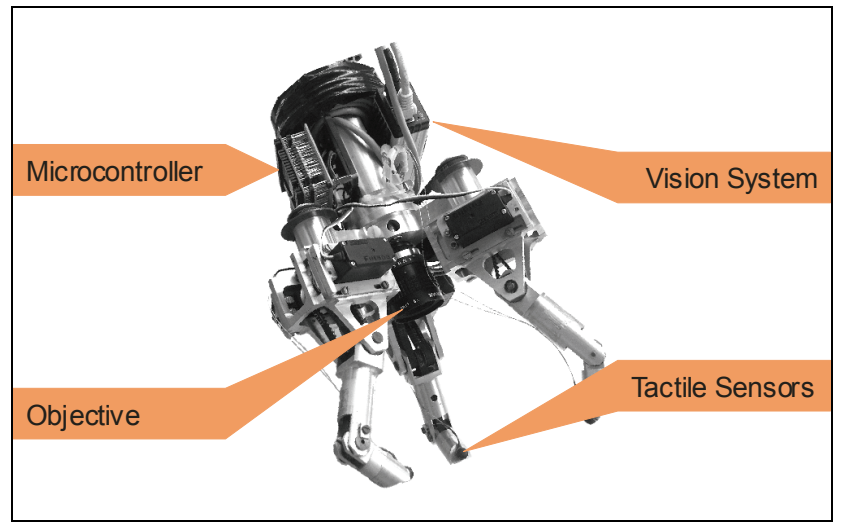

Figure 19: Intelligent three-finger gripper [25].

To imitate the capabilities of human hands, there are research activities in so-called dexterous assembly robots [61]. Human workers assemble dexterously with dexterous hands and with intelligent sensing. Such human-like work has been tried to imitate for robots. These dexterous robots need dexterous hands and fingers and sensory feedback. Also the robot arm is required to be doublejointed. Such assembly robots will realise a fully autonomous assembly but are still under development [61].

Aiyama et al. proposed a design methodology for the compliance of the fingers of a manipulator to fulfil a sequence of dexterous manipulations onto various objects. The proposed methodology is experimented by a robot with three fingers, each with three direct drive joints. This manipulator handles a box in a compact array of six boxes. The first one of the fingers tumbles one box to make two side faces free from the obstacles. Then the other two grasp both the sides and pick it up [2]. 


\section{AUTONOMOUS PARTS, SUBASSEMBLIES, AND PRODUCTS}

To realise autonomous assembly processes, a strict product design for assembly is assumed. Products become more modular, and even reconfigurable to some degree [48]. Furthermore, the final product as well as subassemblies and parts need to be connected with their virtual data to realise autonomous assembly towards selfassembly. This connection is already realised on product level using the electronic product code or similar concepts, but need further research and practical tests to realise also intelligent parts and even raw materials.

In literature, a product whose information content is permanently bound to its material content is often called "intelligent product". McFarlane et al. defined an intelligent product as follows [66]: "An intelligent product is a physical and information based representation of an item which:

1. possesses a unique identification,

2. is capable of communicating effectively with its environment,

3. can retain or store data about itself,

4. deploys a language to display its features, production requirements etc.,

5. is capable of participating in or making decisions relevant to its own destiny."

These characteristics enable the intelligent product to act autonomously and therefore we use the terms "intelligent product" and "autonomous product" interchangeably.

The Collaborative Research Centre "Autonomous Cooperating Logistic Processes: A Paradigm Shift and Its Limitations" at the University of Bremen, Germany, investigates the opportunities of autonomous control of logistic processes that are provided by autonomous logistic objects such as parts, products or packages. The autonomy of the objects is enabled by Ubiquitous Computing technologies which will realise the "Internet of Things" (Figure 20). The goal of autonomous cooperating objects within a logistic system is to reach flexibility, adaptability and reactivity to dynamically changing external influences while maintaining the global goals [76], [125].

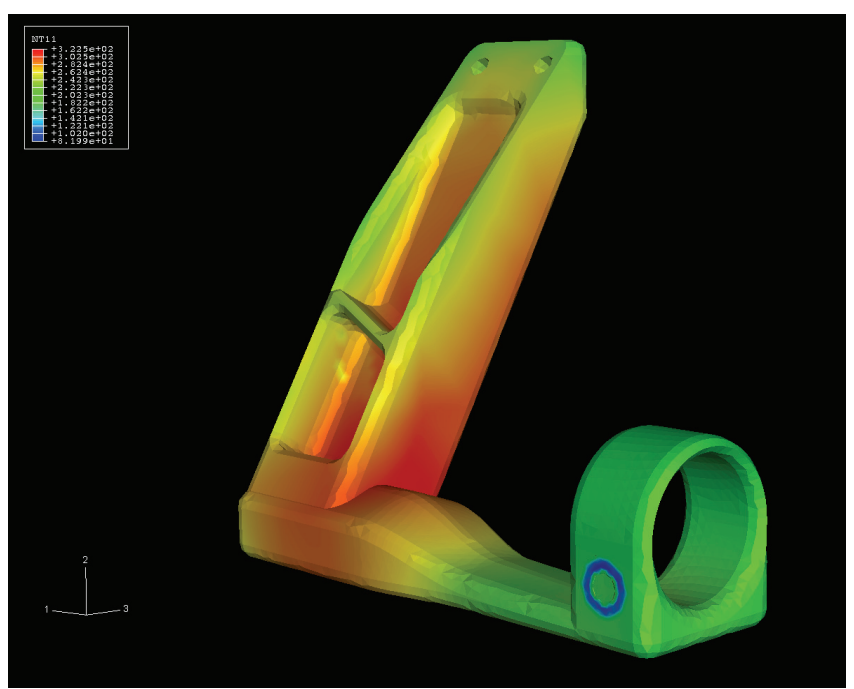

Figure 21: Simulation of the heat diffusion during die casting and the impact of heat on the RFID device [12], [13].

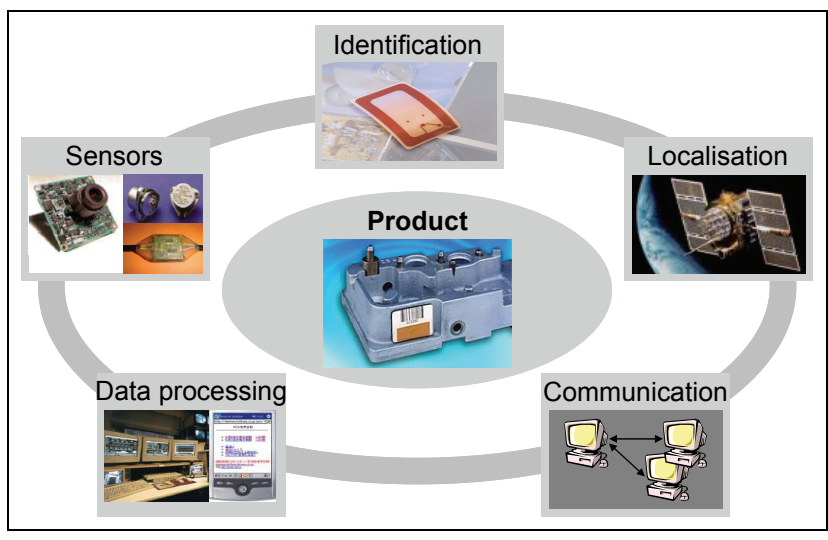

Figure 20: Autonomous product and enabling technologies.

Busse et al. developed a method to integrate RFID devices into die casting metal parts [12], [13]. They analysed the influence of the fusion heat on the moulded RFID device. To design the cast part with respect to the integration of an RFID device, they used simulation tools and the Finite Elements Method to determine the heat diffusion and to design the dielectric gap and the insulating layer (Figure 21). To analyse the functional capabilities of the RFID device after the casting process, Busse et al. made prototypes of die casting aluminium part with integrated RFID device (Figure 22).

Scholz-Reiter et al. are currently developing a method for an autonomous product construction cycle [125]. A product construction cycle is the time span from the release of the manufacturing order through the finishing of the final product. This product construction cycle refers to the job steps during manufacturing and assembly. Based on present customers' orders and possible product variants, the intelligent parts and subassemblies autonomously decide during the manufacturing and assembly process, which final product will be made and which customer order will be served. This will lead to more flexibility and adaptability by using a loose and situational allocation of product variants and customer orders instead of having fixed allocations. Prerequisite for an autonomous product construction is the realisation of intelligent parts such as the presented die casting aluminium part (Figure 22).

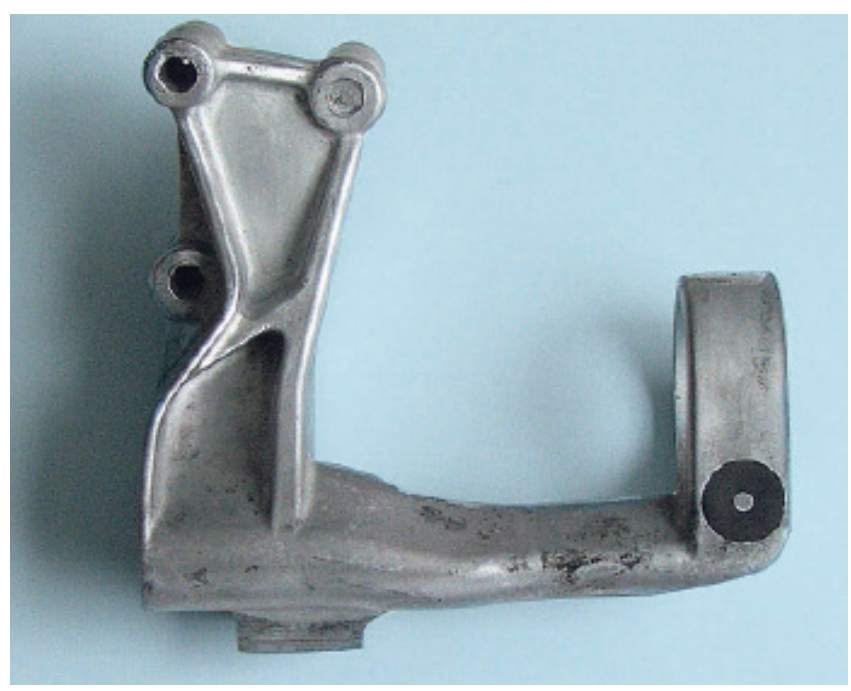

Figure 22: Die casting aluminium part with integrated RFID device [12], [13] 
McFarlane et al. discussed connections between manufactured components or products and product data in the internet using automated identification technologies (Auto ID) and the role of an intelligent product in enhancing existing distributed, intelligent control systems [66]. They illustrated the way in which an Auto ID based control systems might operate in a production environment using a cell for the assembly of a simple electrical meter box and considering both conventional and distributed control strategies. Three kinds of components are used to assemble two kinds of products.

The introduction of product identity data into the conventional control system ensured the arrival of the correct items for assembly and to track the product (and its subcomponents) through the different stages of assembly. The addition of Auto ID data enables the system to handle the following scenarios:

- Item Identifiability: randomly arriving components can be sorted both in terms of product type and also item identifier so that specific items can be preassigned to particular orders,

- Traceability and Quality Error Management: direct tracking of the items moving through assembly enables an accurate status of each item to be maintained in a suitable data store. This provides correlation information that can be used with any error - both product and process - that is detected, enabling simpler fault finding.

These enhancements are essential information oriented improvements to the operation of the assembly cell, reflecting the fact that the Auto ID data do not directly alter the control operations.

By replacing the conventional control by a distributed control environment, orders are represented as product holons and machines and robots as resource holons. There is no predetermined schedule or control for the assembly cell. Here, the customer order generates product specification/recipe software which is embedded in a product agent which negotiates on behalf of the order to have the product made on the resource holons that are available. Furthermore, tagged components required for the assembly are scanned and automatically synchronised with product software which updates during production. Hence the components effectively belong to the customer from this point on. Next, the product holon drives its own manufacturing sequence via negotiation with production resources but - as was the case for the conventional control system - with the Auto ID system in place it is possible to track the product (and its subcomponents) through the different stages of assembly. This information also makes reorganisation of production simple both in terms of the information and control systems and also the physical operations [66].

McFarlane et al. enhanced the concept of the product driven assembly towards autonomous control of the whole supply chain [67].

Ilie-Zudor et al. proposed a product-centric application development and using design patterns to link related webservices directly to the electronic identity of products. To identify and track products the ID@URI identification scheme is advocated. The scheme combines serial numbers and URLs to produce globally unique product identifiers. The TraSer-project - aiming at implementing an open-source solution platform for product centric webservices - has been started in 2006. Based on the first phase of the project, Ilie-Zudor et al. outlined differences and advantages of the TraSer-approach compared to other existing approaches. [47]

\section{FUTURE RESEARCH}

The ManuFuture initiative emphasised four main directions of future research in manufacturing: adaptive, digital, knowledge-based, and networked manufacturing [126]. The approach of autonomous processes - applied in assembly in this special case as well as in manufacturing and logistics in general - fits these requirements. Future research in autonomous processes has to combine the fields of (i) Reconfigurable Manufacturing Systems, (ii) distributed Production Planning and Control using intelligent computation methods and (iii) intelligent and autonomous products, parts and materials using Auto ID and Ubiquitous computing technologies.

Most relevant research topics to be addressed in Reconfigurable Manufacturing Systems of the future are system reconfiguration capabilities including machine modularity and ease of upgrading system capacity or to new technologies as well as the costs of reconfiguration [48]. There will be a necessity for a holistic approach covering the entire system life cycle, from design (design of systems for reconfigurations, system cost) to installation (system ramp up), from use (maintenance) to reconfiguration (Reconfigurable Systems) [48].

Future methods for Production Planning and Control must provide on-line, reactive, opportunistic scheduling of multiple products simultaneously. Synchronous simulation must be provided to enable fast rescheduling. Intelligent decision methods must be used so as to take multiple criteria into account [10]. Future Production Planning and Control systems have to turn to closed-loop controllers which continuously adapt the manufacturing system towards the required state und functionality. Such closedloop control systems will be realised by a real-time information feedback using Auto ID technologies [24]. This shift from off-line planning systems to on-line control systems will change the system architecture and requires additional distributed control units beneath the central ERP system.

How to coordinate such distributed control units close to the physical material flow brings us to the research field of software agents and multi-agent systems. Monostori et al. [69] stated that the major challenge in the deployment of coordination and decision technologies for multi-agent systems is the achievement of complex, adaptive, and flexible collective behaviour in the network. This holds especially for fine-grained agents. The key issue is how to engineer multi-agent systems that exhibit purposive, goaldirected oriented behaviour at the system level by relying on their emergent nature. Generally, how can we design for emergence? Is there any way to guarantee that the system avoids undesirable paths? How can we specify safeguards if we have to anticipate the unexpected? Monostori et al. argued that we need further research in characterising interactions that may or may not produce emergent phenomena, explore its root causes (such as the dimensionality and connectivity of agents, the flow of information among them, and the propagation of constraints) and develop predictive theories [69].

Independent from the specific domain of manufacturing and assembly, today's and future information and communication technologies will be used to realise the socalled "Internet of Things" where everyday objects get the properties of a computer in the internet. Resulting from this trend, the main question for production research is: How can we use the "Internet of Things" to improve our manufacturing and assembly processes? One of the research tasks is the embedding of intelligence into materials, parts, and subassemblies to realise autonomous items. Research has to find techniques that are suitable for creating agents that can be embedded into assembly infrastructures and products. 
Furthermore, these embedded agents are critical to both providing required functionality and to managing the complexity associated with using embedded systems. The profusion of networking from conventional computers down to robots and appliances is set to create a highly complex environment which will present numerous difficult scientific challenges to scientists and society [40].

Finally, autonomous processes will change the working environment of employees both on the operative level and in management. Due to the convergence of control systems and physical systems, parts of the planning and control activities will be shifted from the management offices down to the shop floor. This requires extensive research in the resulting organisational structures and in the education and training of both workers and management. The new information and communication technologies will enrich human work but requires new ways for the cooperation of people and technology. Autonomous processes should support human's capabilities such as knowledge, experience and creativity rather than to replace human activities.

\section{SUMMARY}

This keynote paper gave a survey of autonomous processes in assembly systems which are located on the intersection of Reconfigurable Assembly Systems, distributed Production Planning and Control and intelligent computation methods.

After an introduction, section 2 gave an overview on principles of autonomy for both physical and control systems and introduced autonomous resources, products and processes. Sections 3 to 6 presented the state of the art in this field, classified with regard to the four levels of an assembly system. Section 3 gave an overview on autonomous processes on system level which included the design of autonomous assembly systems, scheduling and control of assembly orders and routing and transport of parts and subassemblies. Section 4 dealt with autonomous processes within both manual, automatic and hybrid assembly cells. This also included autonomy of workers and groups. Section 5 presented research results on autonomous robots as well as autonomously controlled transport systems and section 6 gave an overview on autonomous devices such as part feeders and grippers. Section 7 was dedicated to autonomous parts, subassemblies and products which are able to allocate resources by themselves and route autonomously through the assembly system using recent information and communication technologies. Section 8 gave an outlook to future research in autonomous assembly.

To sum up, we would like to use Table 1, adopted from Jovane et al. [48], to show the evolution of manufacturing paradigms from Flexible Manufacturing Systems over Reconfigurable Systems towards Autonomous Manufacturing Systems. These paradigm shifts are driven by changing market demands and the corresponding requirements to the manufacturing systems. To remain competitive, one of the major characteristics of future manufacturing companies is their changeability [119].

Autonomous Manufacturing Systems will support these frequent or even permanent changes of the system. Using the modularity of both the physical and the control system, the ability to change both capacity and functionality becomes system-inherent. This will lead to self-x characteristics such as self-adaptation, self-optimisation, and self-organisation of the system. This means the automation - originally introduced to relieve the workers of monotone work - will additionally be used to support the employees of a manufacturing company in frequent reconfiguration activities.

\section{ACKNOWLEDGMENTS}

The authors wish to thank all those colleagues who sent articles and information material about their work, in particular Prof. T. Arai, Prof. H. Bley, Prof. G. Chryssolouris, Prof. N.A. Duffie, Prof. K. Feldmann, Prof. J. Fleischer, Prof. S.J. Hu, Prof. Y. Koren, Prof. J. Krüger, Prof. A.R. Mileham, Prof. L. Monostori, Prof. G. Schuh, Prof. G. Seliger, Prof. D. Spath, Prof. T. Tolio, Prof. T. Tomiyama, Prof. K. Ueda, Prof. A. Watanabe, and Prof. H. Yoshikawa.

\begin{tabular}{|c|c|c|c|}
\hline Manufacturing paradigm & $\begin{array}{c}\text { Flexible } \\
\text { Manufacturing Systems }\end{array}$ & $\begin{array}{c}\text { Reconfigurable } \\
\text { Manufacturing Systems }\end{array}$ & $\begin{array}{c}\text { Autonomous } \\
\text { Manufacturing System }\end{array}$ \\
\hline Period of time & $1980 s$ & $1990 s$ & $2000 s$ \\
\hline Market demands & $\begin{array}{c}\text { Variety of products, } \\
\text { Small volume per product }\end{array}$ & $\begin{array}{l}\text { Customized products, } \\
\text { Fluctuating demand }\end{array}$ & $\begin{array}{l}\text { Personalized products, } \\
\text { Turbulent markets }\end{array}$ \\
\hline $\begin{array}{l}\text { Requirements to } \\
\text { manufacturing systems }\end{array}$ & Flexibility & $\begin{array}{l}\text { Adaptability, } \\
\text { Changeability }\end{array}$ & $\begin{array}{l}\text { Self-Adaptation, } \\
\text { Self-Optimisation, } \\
\text { Self-Organisation }\end{array}$ \\
\hline Manufacturing concepts & $\begin{array}{c}\text { CIM, } \\
\text { Flexible automation }\end{array}$ & $\begin{array}{c}\text { HMS, } \\
\text { Reconfigurable systems }\end{array}$ & $\begin{array}{l}\text { Ubiquitous Computing, } \\
\text { Autonomous systems }\end{array}$ \\
\hline Control Concept & $\begin{array}{l}\text { Central control system, } \\
\text { Hierarchical structure }\end{array}$ & $\begin{array}{l}\text { Central and decentralised } \\
\text { controls, dynamic structure }\end{array}$ & $\begin{array}{l}\text { Autonomous control, } \\
\text { Heterarchical structure }\end{array}$ \\
\hline \multirow{2}{*}{ Realisation } & Monolithic PPC systems & Multi-agent systems & $\begin{array}{l}\text { Ubiquitous Computing } \\
\text { Technologies }\end{array}$ \\
\hline & $\begin{array}{c}\text { CNC machining centres, } \\
\text { Robots }\end{array}$ & $\begin{array}{c}\text { Modularity, } \\
\text { Standardised interfaces }\end{array}$ & $\begin{array}{l}\text { Integration of control into } \\
\text { sub-systems, machines, } \\
\text { components, and parts }\end{array}$ \\
\hline
\end{tabular}

Table 1: Evolution of manufacturing paradigms (adapted from [48]). 


\section{REFERENCES}

[1] Alexopoulos, K., Mourtzis, D., Papakostas, N., Chryssolouris G., 2006, DESYMA - Assessing Flexibility for the Lifecycle of Manufacturing Systems, International Journal of Production Research 45/7: 1683-1694.

[2] Aiyama, Y., Arai, T., Ota J., 1998, Dexterous Assembly - Manipulation of a Compact Array of Objects, Annals of the CIRP 47/1:13-16

[3] Arai, T., Ota, J., Aiyama, Y., 1997, Assembly of Nongrasping Manipulation, Annals of the CIRP 46/1:905910.

[4] Arai, T, Aiyama, Y., Maeda, Y., Sugi, M., Ota, J., 2000, Agile Assemly System by Plug and Produce, Annals of the CIRP 49/1:1-4.

[5] Arai, T., Maeda, Y., Kikuchi, H., Sugi, M., 2002, Automated Calibration of Robot Coordinates for Reconfigurable Assembly Systems, Annals of the CIRP 51/1:5-8

[6] Armbruster, D., de Beer, C., Freitag, M., Jagalski T., Ringhofer, C., 2006, Autonomous Control of Production Networks using a Pheromone Approach, Physica A: Statistical Mechanics and its Applications 363/1:104-114.

[7] Bard, J., 1989, Assembly Line Balancing with Parallel Workstations and Dead Time, International Journal of Production Research, 27/6:1005-1018.

[8] Baybars, I., 1986, A Survey of Exact Algorithms for the Simple Assembly Line Balancing Problem, Management Science, 32/8:909-932.

[9] Bley, H., Reinhart, G., Seliger, G., Bernardi, M., Korne, T., 2004, Appropriate Human Involvement in Assembly and Disassembly, Annals of the CIRP 53/2:487-558.

[10] Brussel, H. Van, 1990, Planning and Scheduling of Assembly Systems, Annals of the CIRP 39/2:637644.

[11] Brussel, H. Van, Wyns, J., Valckenaers, P., Bongaerts, L., Peeters, P., 1998, Reference Architecture for Holonic Manufacturing Systems: PROSA", Computers in Industry 37/3:255-274.

[12] Busse, M.; Wöstmann, F.-J.; Müller, Th.; Melz, T.; Spieß, P., 2006, Intelligente Druckgussteile, Metall 11:738-741.

[13] Busse, M.; Wöstmann, F.-J.; Müller, Th.; Melz, T.; Spies, P., 2006, Intelligente Gussteile - Einsatz adaptronischer Komponenten in Kombination mit Gussteilen, Gießerei-Rundschau 53:96-99.

[14] Chryssolouris, G., 1996, Flexibility and its Measurement, Annals of the CIRP 45/2:581-587.

[15] Chryssolouris, G., Papakostas, N., Mourtzis, D., 2000, A Decision-Making Approach for Nesting Scheduling: A Textile Case, International Journal of Production Research 38/17:4555-4564.

[16] Duffie, N., 1982, An Approach to the Design of Distributed Machinery Control Systems, IEEE Trans. on Industry Applications IA-18/4:435-442.

[17] Duffie, N., Hartwick, J., Humphrey, B., 1986 , Hierarchical and Non-Hierarchical Manufacturing Cell Control with Dynamic Part-Oriented Scheduling, Proc. of NAMRC-XIV, Minneapolis, MN, 504-507.

[18] Duffie, N., Chitturi, R., Mou, J., 1988, Fault-Tolerant Heterarchical Control of Heterogeneous Manufacturing System Entities, J. of Manufacturing Systems, 7/4:315-328.

[19] Duffie, N., 1990, Synthesis of Heterarchical Manufacturing Systems, Computers in Industry, 14:167-174
[20] Duffie, N., Prabhu, V., 1994, Real-Time Distributed Scheduling of Heterarchical Manufacturing Systems, J. of Manufacturing Systems, 13/2:94-106.

[21] Duffie, N., Prabhu, V., 1995, Distributed SystemLevel Control of Vehicles in a High-Performance Material Transfer System, IEEE Trans. on Control Systems Technology, 3/2:212-217.

[22] Duffie, N., Li, L., Prabhu, V., Lorenz, R., 1995, Ultrafast Material Transfer Network, Proc. of SPIE Photonics East '95 Symp., Philadelphia, PA, 200-213.

[23] Duffie, N., Prabhu, V., Kaltjob, P., 2002, Closed-Loop Real Time Cooperative Decision Making Dynamics in Heterarchical Manufacturing Systems, J. of Manufacturing Systems, 21/6:409-418.

[24] Feldmann, K. Slama, S., 2001, Highly Flexible Assembly - Scope and Justification. Annals of the CIRP 50/2:489-498.

[25] Feldmann, K., Junker, S., Wolf, W., 2005, Innovative Mechatronic Devices for Flexible Automated Assembly Systems. Annals of the German Academic Society for Production Engineering, 213-218.

[26] Feldmann, K., Wolf, W., 2005, Autonom navigierende Fahrerlose Transportsysteme in der Produktion. In: Levi, P., Schanz, M., Lafrenu, R., Avrutin, V. (eds.): Autonome Mobile Systeme 2005, Springer, 261-267.

[27] Feldmann, K., Weber, M., Wolf, W., 2006, Decentralized Structure Recognition and Automated Network Configuration for Plug\&Produce-able Modular Assembly Systems. Annals of the German Academic Society for Production Engineering, 235240.

[28] Feldmann, K., Wolf, W., Weber, M., 2006, Self Organizing Material Flow for Plug\&Produce-able Modular Assembly Systems. Annals of the German Academic Society for Production Engineering, 229234.

[29] Feldmann, K., Weber, M., Wolf, W., 2007, Design of a Theoretical Holistic System Model as Base of Construction Kits for Building Plug\&Produce-able Modular Production Systems. Annals of the German Academic Society for Production Engineering, to appear.

[30] Feldmann, K., Wolf, W., Weber, M., 2007, Design of a Formal Model for the Specification of Agent Platforms Based on Plug\&Produce-able Production Systems. Annals of the German Academic Society for Production Engineering, to appear.

[31] Fischer, K., 1999, Agent-based Design of Holonic Manufacturing Systems, Robotics and Autonomous Systems 27/1-2:3-13.

[32] Fleischer, J., Volkmann, T., Krahtov, L., 2004, Wirtschaftliche Automatisierung der Mikromontage in der Kleinserienfertigung durch intelligente und autonome Mikromontagevorrichtungen, wt Werkstattstechnik online 94/9:389-394.

[33] Fleischer, J., Volkmann, T., Krahtov, L., 2005, Konzeption einer skalierbaren Mikroproduktion Planungssystematik und Plattform von Prozessmodulen zur Produktion mikromechatronischer Produkte, wt -Werkstattstechnik online, 95/8:705 -711.

[34] Freeman, H., 1961, On the Encoding of Arbitrary Geometric Configurations, IRE Trans. Electron. Comput., EC-10:260-268.

[35] Freiheit, T., Shpitalni, M., Hu, S. J., Koren, Y., 2003 Designing Productive Manufacturing Systems without Buffers, Annals of the CIRP 52/1:105-108. 
[36] Freiheit, T., Shpitalni, M., Hu, S. J., 2004, Productivity of Paced Parallel-Serial Manufacturing Lines with and without Crossover, Transactions of the ASME, Journal of Manufacturing Science and Engineering 126/2:361-367.

[37] Freiheit, T., Shpitalni, M., Hu, S. J., Koren, Y., 2004, Productivity of Synchronized Machine Lines with Flexible Reserve Capacity, International Journal of Production Research 42/10:2009-2027.

[38] Freiheit, T., Koren, Y., and Hu, S. J., Koren, Y., 2004, Productivity of Synchronized Parallel Production Lines with Unreliable Machines and Material Handling, IEEE Transactions of Automation Science and Engineering 1/1:98-103.

[39] Fujita, N., 1988, Assembly of Blocks by Autonomous Assembly Robot with Intelligence, Annals of the CIRP 37/1:33-36.

[40] Hagras, H., Callaghan, V., Colley, M., 2005, Intelligent Embedded Agents, Information Sciences 171/4:289-292.

[41] Hirabayashi, H. et al., 1983, Traveling Assembly Center, Proc. 13th International Symposium on Industrial Robots (ISIR), Chicago, USA.

[42] Hoska, D.R., 1988, Fixtureless Assembly Manufacturing, Manuf Eng. 100:49-54.

[43] Hu, M.K., 1962, Visual Pattern Recognition by Moment Invariants, IRE Trans. Inform. Theory, 8:179187.

[44] Hu, S.J., 1997, Stream-of-Variation Theory for Automotive Body Assembly, Annals of the CIRP 46/1:1-4.

[45] Hu, S.J., Camelio, J.A., 2006, Modeling and Control of Compliant Assembly Systems, Annals of the CIRP 55/1:19-22.

[46] Huang, B., Gou, H., Liu, W., Li, Y., Xie, M., 2002, A Framework for Virtual Enterprise Control with the Holonic Manufacturing Paradigm, Computers in Industry 49/3:299-310.

[47] Ilie-Zudor, E., Främling, K., Holstrom, J., Monostori, L., 2006, Identity-based Tracking of Products and Product Data in Changing Networks, Proceedings of the 8th International Conference on The Modern Information Technology in the Innovation Processes of the Industrial Enterprises, Budapest, Hungary, 1522.

[48] Jovane, F., Koren, Y., Boër, C.R., 2003, Present and Future of Flexible Automation: Towards New Paradigms, Annals of the CIRP 52/2:543ff.

[49] Kondoh, S., Umeda, Y., Yoshikawa, H., 1998, Development of Upgradeable Cellular Machines for Environmentally conscious Products, Annals of the CIRP 47/1:381-384.

[50] Kondoh, S., Umeda, Y., Tomiyama, T., Yoshikawa H., 2000, Self Organization of Cellular Manufacturing Systems, Annals of the CIRP 49/1:347-350.

[51] Kondoh, S., Sato, R.K., Tomiyama, T., Umeda, Y., 2000, Self-Organization of the Cellular Manufacturing System, CIRP Journal of Manufacturing Systems 30/6:507-513.

[52] Kondoh, S., Tomiyama, T., Umeda, Y., 2001, Morphological Design of a Manufacturing System based on the Concepts of Cellular Machines, CIRP Journal of Manufacturing Systems 31/1:83-87.

[53] Koren, Y., Heisel, U., Jovane, F., Moriwaki, T., Pritschow, G., Ulsoy, G., Van Brussel, H., 1999, Reconfigurable Manufacturing Systems, Annals of the CIRP, 48/2:527-540.
[54] Krönke, L., Krönke Consult, Krefeld, Germany, www.kroenke-consult.de

[55] Krüger, J., Nickolay, B., Heyer P., Seliger, G., 2005, Image based 3D Surveillance for Flexible Man-RobotCooperation, Annals of the CIRP 54/1:19-22.

[56] Krüger, J., Bernhardt, R., Surdilovic, D., Spur, G., 2006, Intelligent Assist Systems for Flexible Assembly Annals of the CIRP 55/1:29-32.

[57] Lien, T.K., Rasch, F.O., 2001, Hybrid AutomaticManual Assembly Systems, Annals of the CIRP 50/1:21-24

[58] Maier-Speredelozzi V., Hu, S. J., 2002, Selecting Manufacturing System Configurations Based on Performance Using AHP, Technical Paper, Society of Manufacturing Engineers MS, n MS02-179, 1-8.

[59] Maier-Speredelozzi V., Koren, Y., Hu, S. J., 2003, Convertibility Measures for Manufacturing Systems, Annals of the CIRP 52/1:367-370.

[60] Maier-Speredelozzi V., Freiheit, T., Hu, S. J., 2003, Convertibility and Productivity of Manufacturing System Configurations, Proceedings of the American Society of Mechanical Engineers, Manufacturing Engineering Division, 14/1:381-390.

[61] Makino, H., Arai, T. 1994, New Developments in Assembly Systems, Annals of the CIRP 43/1:501512.

[62] Marik, V., McFarlane, D., Valckenaers, P. (eds.), 2003, Holonic and Multi-Agent Systems for Manufacturing, Springer, Berlin.

[63] Marik, V., Brennan, R.W., Pechoucek, M. (eds.), 2005, Holonic and Multi-Agent Systems for Manufacturing, Springer, Berlin.

[64] Márkus, A.; Kis, T.; Váncza, J.; Monostori, L., 1996, A Market Approach to Holonic Manufacturing, Annals of the CIRP 45/1:433-436.

[65] Mathews, J., 1995, Organizational Foundations of Intelligent Manufacturing Systems - the Holonic Viewpoint, Computer Integrated Manufacturing Systems 8/4:237-243.

[66] McFarlane, D., Sarma, S., Chirn, J.-L., Wong, C.Y., Ashton, K., 2002, The Intelligent Product In Manufacturing Control And Management, Proc IFAC World Congress 2002, Barcelona, 49-54.

[67] McFarlane, D., Zaharudin, A., Wong, C.Y., 2002, The Intelligent Product Driven Supply Chain, Proceedings of IEEE International Conference on Systems, Man and Cybernetics 4/1:6.

[68] Mehrabi, M., Ulsoy, G., Koren, Y., 2000, Reconfigurable Manufacturing Systems: Key to Future Manufacturing, Journal of Intelligent Manufacturing 11/4:403-419.

[69] Monostori, L.; Váncza, J.; Kumara, S.R.T.: Agentbased Systems for Manufacturing, Annals of the CIRP 55/2:697-720.

[70] Papakostas, N., Mourtzis, D., Bechrakis, K., Chryssolouris, G. and Doukas, D., Doyle, R., 1999, A Flexible Agent Based Framework for Manufacturing Decision-Making, In: Ashayeri, J., Sullivan, W., Munir Ahmad, M. (eds.): Proceedings of the 9th Flexible Automation and Intelligent Manufacturing Conference (FAIM99), Begell House Inc., 789-800.

[71] Papakostas, N., Makris, S., Alexopoulos, K., Mavrikios, D., Stournaras, A., Chryssolouris, G., 2006, Modern Automotive Assembly Technologies: Status and Outlook, Proceedings of the 1st CIRP International Seminar on Assembly Systems, 39-44. 
[72] Santochi, M., Dini, G., 1998, Sensor Technology in Assembly Systems, Annals of the CIRP, 47/2:503524.

[73] Schipper, D.A., 2001, Mobile Autonomous Robot Twente - A Mechatronics Design Approach, PhD thesis, University of Twente, http://purl.org/utwente/36603

[74] Scholz-Reiter, B., Scharke, H., Hucht, A., 1999, Flexible Robot-Based Disassembly Cell for Obsolete TV-Sets and Monitors, Robotics and Computer Integrated Manufacturing 15/3:247-255.

[75] Scholz-Reiter, B., Scharke, H., Li, W.C., 2000, A Methodology to Derive Disassembly Information for Obsolete Appliances, Proceedings International CIRP Design Seminar, Haifa, Israel, 217-222.

[76] Scholz-Reiter, B., Windt, K., Freitag, M., 2004, Autonomous Logistic Processes: New Demands and First Approaches. Proc. 37th CIRP International Seminar on Manufacturing Systems. Budapest, Hungaria, 357-362.

[77] Scholz-Reiter, B., Echelmeyer, W., Morales-Kluge, E.:, 2005, Verfahren und System zur automatisierten Übergabe von Stückgütern zwischen einem Lager und einem Transportmittel oder zwischen zwei Transportmitteln sowie Stückgut. German Patent DE 102005033112 A1 2007.01.25.

[78] Scholz-Reiter, B., Tervo, J.T., Freitag, M., 2006, Phase Synchronisation in Continuous Flow Models of Production Networks, Physica A: Statistical Mechanics and its Applications 363/1:32-38.

[79] Scholz-Reiter, B., Uckelmann, D., Gorldt, Ch., Hinrichs U., 2006, Einsatz von Auto-ID-Technologien in der Handhabungstechnik, ZWF - Zeitschrift für wirtschaftlichen Fabrikbetrieb, 101/3:97-101.

[80] Scholz-Reiter, B., Gorldt, Ch., Hinrichs U., Tervo, J.T., 2006, Einsatzmöglichkeiten von Ubiquitous Computing und RFID in logistischen Prozessen, 2. Workshop RFID, Intelligente Funketiketten Chancen und Herausforderungen, ITG-Fachbericht 195, VDE-Verlag, Berlin, 1-7.

[81] Schuh, G., Kampker, A., Höhne, T., 2006, Adaptive Logistik - Selbststeuerung in Fertigung und Montage, wt - Werkstattstechnik online 96/5:321-324.

[82] Schuh, G., Höhne, T., Attig, P., 2006, Ansätze zur kognitiven Produktionslogistik. In: Pfohl, H.-Ch.; Wimmer, Th. (Hrsg.): Steuerung von Logistiksystemen - auf dem Weg zur Selbststeuerung. Konferenzband zum 3. BVLWissenschaftssymposium Logistik, Deutscher Verkehrs-Verlag Hamburg, 395-407.

[83] Seliger, G., Kruetzfeldt, D., 1999, Agent-Based Approach for Assembly Control, Annals of the CIRP, 48/1:21-24.

[84] Son, S.Y., Olsen, T.L., Yip-Hoi, D., 2000, Economic Benefits of Reconfigurable Manufacturing Systems, Proceedings of the Japan USA Flexible Automation Conference, Ann Arbor, Michigan, USA, CD-ROM.

[85] Soni, A.H., 1990, Research Needs and Opportunities in Flexible Assembly Systems, ASME $2^{\text {nd }}$ Conf. on Flexible Assembly Systems, Chicago, USA, 221-228.

[86] Spath, D., 2005, Flexibilität in der deutschen Wirtschaft - Wunsch oder Realität?, Tagungsband zum Berliner Kongress „Arbeit und Organisation - Mit Flexibilität zum Unternehmenserfolg“, 7 pages.
[87] Spath, D., Richter, M., Becker, M., 2005, The Adaptive Business Labour Organisation: A New Concept for Production Competitiveness, Proc. 18 International Conference on Production Research, CD-ROM.

[88] Starr, M.K., 1965, Modular Production - A New Concept, Harvard Business Review, 53/6:131-142.

[89] Stiefbold, O., 1998, Konzeption eines reaktionsschnellen Planungssystems für Logistikketten auf Basis von Software-Agenten (Dissertation), Forschungsberichte aus dem Institut für Werkzeugmaschinen und Betriebstechnik (wbk), Bd. 84, Universität Karlsruhe.

[90] Stiefbold, O., 1999, Werkstattauftragsplanung und -steuerung mit Multi-Agenten-Systemen. wt Werkstattstechnik, 89/1-2:12-15.

[91] Sun, H., Venuvinod, P.K., 2001, The Human Side of Holonic Manufacturing Systems, Technovation 21/6:353-360.

[92] Tang, L., Yip-Hoi, D., Wang, W., and Koren, Y., 2003, Concurrent Line-balancing, Equipment Selection and Throughput Analysis for Multi-part Optimal Line Design, Proceeding of the CIRP 2nd International Conference on Reconfigurable Manufacturing 6/12:71-82.

[93] Tamaki, K. et al., 1993, A Restructurable Assembly Center Employing Mobile DD-Robots, Proc. $24^{\text {th }}$ Int. Symp. on Industrial Robots, 119-126.

[94] Teti, R., Kumara, S.R.T., 1997, Intelligent Computing Methods for Manufacturing Systems, Annals of the CIRP 46/2:629-652.

[95] Tillema, H.G., 1993, MART - An Overview of the Mobile Autonomous Robot Twente Project, University of Twente, http://doc.utwente.nl/19858/

[96] Travaini, E., Pedrazzoli, P., Rinaldi, R., Boër, C.R., 2002, Methodological Approach and Reconfiguration Tool for Assembly Systems, Annals of the CIRP 51/1:9-12.

[97] Ueda, K., Vaario, J., Ohkura, K., 1997, Modelling of Biological Manufacturing Systems for Dynamic Reconfiguration, Annals of the CIRP 46/1:343-346.

[98] Ueda, K., Hatono, I., Fujii, N., Vaario, J., 2000, Reinforcement Learning Approaches to Biological Manufacturing Systems, Annals of the CIRP 49/1:343-346

[99] Ueda, K., Markus, A., Monostori, L., Kals, H.J.J., Arai, T., 2001, Emergent Synthesis Methodologies for Manufacturing, Annals of the CIRP 50/2:335-365.

[100] Ueda, K., Hatono, I., Fujii, N., Vaario, J., 2001, LineLess Production System Using Self-Organization: A Case Study for BMS, Annals of the CIRP 50/1:319322.

[101]Ueda, K., Fujii, N., Hatono I., Kobayashi M., 2002, Facility Layout Planning Using Self-Organization Method, Annals of the CIRP 51/1:399-402.

[102] Ueda, K., Lengyel, A., Hatono, L., 2004, Emergent Synthesis Approaches to Control and Planning in Make to Order Manufacturing Environments, Annals of the CIRP 53/1:385-388.

[103] Ueda, K., Kito, T., Fujii, N., 2006, Modeling Biological Manufacturing Systems with Bounded-Rational Agents, Annals of the CIRP 55/1:469-472.

[104] Ueda, K., 2007, Emergent Synthesis Approaches to Biological Manufacturing Systems, Proc. 3rd International CIRP Conference on Digital Enterprise Technology (DET '06), CD-ROM. 
[105] Valckenaers, P., 2001, Editorial of the Special Issue on Holonic Manufacturing Systems, Computers in Industry, 46/3:233-234.

[106] Valckenaers, P., Van Brussel, H., 2005, Holonic Manufacturing Execution Systems, Annals of the CIRP 54/1:427-430.

[107]Wang, Q., Owen, G.W., Mileham, A.R., 2005, Comparison Between Fixed and Walking Worker Assembly Lines, Proceedings Institution of Mechanical Engineers, Part B: Journal of Engineering Manufacture, Short Communications in Manufacture and Design 219/B11:845-848.

[108]Wang, Q., Owen, G.W., Mileham, A.R., 2005, Assessing the Effect of Work Time Variations for a Linear Walking-fitter Assembly Line, Proc 3rd International Conference on Manufacturing Research (ICMR 2005), Cranfield, CD-ROM, File E2Wang.

[109]Wang, Q., Owen, G.W., Mileham, A.R., 2007, Determining Numbers of Workstations and Operators for a Linear Walking-worker Assembly Line, IJCIMS, to appear.

[110] Watanabe, A., Sakakibara, S., Ban, K.. Yamada, M., Shen, G., Arai, T., 2005, Autonomous Visual Measurement for Accurate Setting of Workpieces in Robotic Cells, Annals of the CIRP 54/1:13-16.

[111]Watanabe, A., Sakakibara, S., Ban, K., Yamada, M., Shen, G., Arai, T., 2006, A Kinematic Calibration Method for Industrial Robots Using Autonomous Visual Measurement, Annals of the CIRP 55/1:1-4.

[112]Webbink, R.F., Hu, S.J., 2005, Automated Generation of Assembly System Design Solution, IEEE Transactions on Automation Science and Engineering 2/1:32-39.

[113] Westkämper, E., Feldmann, K., Reinhard, G., Seliger, G., 1999, Integrated Development of Assembly and Disassembly, Annals of the CIRP 48/2:557-565.

[114]Westkämper, E., 2002, Platform for the Integration of Assembly, Disassembly and Life Cycle Management, Annals of the CIRP 51/1:33-36.

[115] Wiendahl, H.-P., Garlichs, R., Zeugträger, K., 1991, Modelling and Simulation of Assembly Systems, Annals of the CIRP 40/2:577-585.
[116] Wiendahl, H.-P., Garlichs R., 1994, Decentral Production Scheduling of Assembly Systems with Genetic Algorithm, Annals of the CIRP 43/1:389-392.

[117] Wiendahl, H.-P., Scholtissek, P., 1994, Management and Control of Complexity in Manufacturing, Annals of the CIRP 43/2:533-540.

[118] Wiendahl, H. P., Fiebig, C., Hernandez, R., 2002, A Transformable and Reconfigurable Factory: Strategies, Methods and Case Study, Proceedings of the ASME IMECE 2002, New Orleans, USA, CDROM.

[119] Wiendahl, H. P., ElMaraghy, H.A., Nyhuis, P., Zäh, M.F., Wiendahl, H.-H., Duffie, N.A., Kolakowski, M., 2007, Changeable Manufacturing - Classification, Design and Operation, Annals of the CIRP 56/2, to appear.

[120]Womack, J., 1990, The Machine that Changed the World, Rawson Associates, New York, NY, USA.

[121] Yang, S., Wu, C., and Hu, S. J., 2000, Modeling and Analysis of Multi-stage Transfer Lines with Unreliable Machines and Finite Buffers, Annals of Operations Research 93:405-421.

[122] Yoshikawa, H., 1977, A Japanese Project on Fully Automated Factory, Proceedings of the PROLAMAT 76, North-Holland, 1-18.

[123] Yoshikawa, H., 1984, Flexible Manufacturing Systems in Japan, Proceedings of the IFAC World Congress, 2329-2337.

[124]Zhong, W., Huang, Y., Hu, S. J., 2002, Modeling Variation Propagation in Machining Systems with Different Configurations, Proceedings American Society of Mechanical Engineers, Manufacturing Engineering Division 13:91-106.

[125]N.N., 2004, Collaborative Research Centre 637 "Autonomous Cooperating Logistic Processes: A Paradigm Shift and Its Limitations, www.sfb637.unibremen.de

[126] N.N., 2004, Manufuture: A Vision for 2020, Assuring the Future of Manufacturing in Europe, Report of the High-Level Group, EC, November: 1-20. 